\title{
Health Care Decisions as a Family Matter Intrahousehold Education Externalities and the Utilization of Health Services
}

\author{
Magnus Lindelöw \\ The World Bank \\ Centre for Study of African Economies, Oxford University \\ Email: mlindelow@worldbank.org
}

World Bank Policy Research Working Paper 3324, June 2004

The Policy Research Working Paper Series disseminates the findings of work in progress to encourage the exchange of ideas about development issues. An objective of the series is to get the findings out quickly, even if the presentations are less than fully polished. The papers carry the names of the authors and should be cited accordingly. The findings, interpretations, and conclusions expressed in this paper are entirely those of the authors. They do not necessarily represent the view of the World Bank, its Executive Directors, or the countries they represent. Policy Research Working Papers are available online at http://econ.worldbank.org.

I am grateful to the National Statistics Institute (INE) in Mozambique for granting me permission to use the 1996/97 Household Survey. Ken Simler provided invaluable support in accessing and interpreting the data. I have also benefited from comments and suggestions from Marcel Fafchamps, Pieter Serneels, Adriaan Soetevent, and Mattias Lundberg. 


\begin{abstract}
This paper is concerned with the role of education as a determinant of health care choices. The central premise of the paper is that utilization of health services is determined not solely by an individual's own education, but rather by a notion of effective education, which incorporates the educational attainment of other household members. The paper sets out a general framework for representing intrahousehold education externalities, and proposes a number of specific hypotheses concerning the way in which the education of different household members affects health care choices. These hypotheses are tested on data from Mozambique, focusing on maternity services and child immunizations. We draw five major conclusions from the analysis. First, while maternal education seems to be the education variable of primary importance for the health care choices under consideration, the education of other household members has a significant and sometimes large effect. Second, the analysis suggests that while the education of the person (nonspouse) in the household with the highest-level education is important, the level of education of additional household members does not have an impact on health care choices. Third, the data provide no evidence of a gender difference in education externalities. Fourth, we examine the merits of two alternative representations of the education externality, but are unable to conclude unambiguously in favor of one specification over the other.
\end{abstract}




\section{Introduction}

This paper is concerned with the role of education in choices about maternity care and child immunizations. The correlation between education and utilization of health services is well established in the literature (see Strauss and Thomas 1995). Traditionally, empirical analysis has focused on the educational attainment of the person seeking care or, in the case of child health, on maternal education. For maternity care, this is motivated by health care choices being conceived as individual decisions. For child health, the literature has paid attention to both maternal and paternal education, but many contributors have argued that maternal education is of particular importance (Caldwell 1979), and this has been confirmed empirically in many contexts (see Bicego and Boerma 1993). ${ }^{1}$

The focus on individual or maternal education, however, offers only a partial picture of the role of education in decisionmaking. Education proxies for information, cognitive skills, and values (Schultz 1984). These features of education are a public good within a household, or can at least be expected to bring external benefits to other household members. This may operate, for example, through complementarities in knowledge and information between different individuals. The notion of intrahousehold education externalities raises both conceptual questions about how to model the broader effects of education in the decisionmaking process, and empirical questions about the importance of external effects. In particular, beyond the woman's own education, does the educational attainment of other household members - spouse and nonspouse - have an impact on health care choices?

The paper makes three main contributions. First, it offers a general framework for analyzing intrahousehold education externalities and their effect on decisions relating to health care. Second, on the basis of a general framework for analyzing the utilization of health services, it presents empirical evidence from Mozambique concerning the impact of education externalities on childhood immunizations and the utilization of reproductive health services. Finally, it provides some tentative conclusions concerning rival specifications of the conditioning education variables.

The paper is organized as follows. Section 2 briefly reviews the literature on which the analytical and empirical approach is based. Section 3 presents a framework for representing education externalities and also outlines the empirical approach. Section 4 describes the data and key variables in the analysis. Section 5 reports on key findings from the empirical analysis. Section 6 concludes.

\section{Related Literature}

The paper is located at the intersection of two strands of the literature. First, it relates to a broad literature on human capital investments and health production concerned with the demand for health care and the determinants of health outcomes. This literature provides both a theoretical grounding for the role of education in health care demand and empirical evidence of its importance. Second, the paper draws on a

\footnotetext{
${ }^{1}$ Caldwell (1979) argued that maternal education is important because it (a) reduces fatalism in relation to health; (b) conveys a greater capacity of manipulating the world (e.g., knowing how and when to visit health care facilities); and (c) represents a change in the traditional balance of familial relationships.
} 
growing literature on education externalities and their impact on behavior and outcomes.

\subsection{The Effect of Education On Health Care Choices}

There is a broad array of approaches to study the utilization of health services in developing countries. A sizeable anthropological literature has emphasized the role of beliefs, attitudes, and perceptions on health-related behavior. For developing countries, much of this literature has focused on traditional medical practices. However, there have also been a number of studies concerning the use and nonuse of allopathic ("modern") medicine. By focusing on issues relating to sequencing, perceptions of complementarity between different sources of care, and the role of norms, rules, and beliefs in the area of health, these studies have highlighted the complexity of decisionmaking processes in relation to health (see, Ryan 1981, 1998; Ryan and Martinez 1996).

In contrast, following Grossman (1972a; 1972b), much of the economic analysis of health care decisions has been based on a human capital framework, in which health features directly as an argument in the utility function, and is produced in the home through the combination of purchased inputs and time (Becker 1965). Hence, this literature has emphasized the importance of preferences, prices (including shadow prices), and technology, and has highlighted the tradeoffs between the costs of investments in health and the alternative uses of those resources. Health services comprise an important health investment. The costs associated with the utilization of health services include direct monetary costs for consultations, tests, and medication (and possibly internment), but also indirect (monetary and nonmonetary) costs such as foregone income and costs associated with not performing normal activities (paid work, unpaid agricultural or house work, tending to children), and transport costs. Whether these costs are worth incurring depends on both preferences and the technology by which health inputs are transformed into health outcomes.

The human capital framework suggests a number of reasons why the utilization of health services (or human capital investments in general) are likely to be influenced by education. The effects operate through many channels. In part, this is due to the multidimensional nature of the concept of educational outcome or achievement, which includes basic and complex cognitive skills, general knowledge, technical skills, and norms and values (Glewwe 2000). In this sense it may be inappropriate to speak of the effect of education on the demand for health inputs. However, ambiguities about the effect of education also stem from theory, which suggests complex paths of influence. These include (a) efficiency (more educated individuals are better at choosing an appropriate mix of health inputs), (b) technology (more educated individuals make more effective use of health inputs), (c) preferences (education conveys values and norms related to the perceived value of health), (d) income (higher education is associated with higher income and greater demand for health), (e) substitution (education raises the opportunity cost of time and will result in a shift away from labor intensive home production) (Schultz 1984). In general, theory does not offer unambiguous conclusions about the impact of education on the demand for health inputs, thus pointing to the need for an empirical analysis.

Empirical work on the impact of education (and other individual, household, and community factors) has focused on both health outcomes and the demand for 
health inputs. ${ }^{2}$ Most studies have found that higher education, in particular maternal education, results in improved child health (in terms of child mortality and child nutrition), although these findings are not unambiguous (Barrera 1990; Benefo and Schulz 1996; Bicego and Boerma 1993; Caldwell 1979; Desai and Alva 1998; Glewwe 1999; Hobcraft 1993; Hossain 1989; Lavy and others 1996; Wolfe and Behrman 1982, 1984). The relationship between education and health operates primarily through the impact of education on proximate determinants of health, such as feeding and health practices, sanitation, and utilization of health services. This mechanism has also been studied empirically. For example, studies have focused on the impact of education on food nutrient intake and sanitary practices (Cebu Study Team 1991), use and timing of prenatal health services (Behrman and Wolfe 1987; Gertler, Rahman, and Feifer 1993; Guilkey and Riphahn 1998; Panis and Lillard 1994; Pebley, Goldman, and Rodriguez 1996; Sandiford and others 1995; Schwartz and others 1988; Wong and others 1987), and child immunizations (Gage, Sommerfelt, and Piani 1997; Guilkey and Riphahn 1998; Steele, Diamond, and Amin 1996; Streatfield, Singarimbun, and Diamond 1990). Many of these studies also find education to be an important determinant. ${ }^{3}$ Again, maternal education is often found to be more important than paternal education. ${ }^{4}$ The primary importance of maternal education for child health outcomes and the use of health care services may be due to social and cultural factors, whereby there are gender differences in preferences or in the information and skills acquired through education. Alternatively, importance of maternal education may reflect the concentration of benefits from investment in maternal and child health on the mother.

The empirical analysis of these issues is fraught with problems, and these findings are not uncontested. Many studies do not adequately control for unobservables such as individual and household background and school characteristics. For example, there may be common unobservables - preferences or abilities - that determines both the amount of education acquired and human capital outcomes (Behrman and Wolfe 1987; Desai and Alva 1998; Hobcraft 1993).

Similarly, for some issues, educational attainment or at least health knowledge may respond endogenously to unobserved health endowments. Although these factors may lead to bias in some contexts if not addressed in the analysis, there seems to be a general consensus that education is an important determinant of the demand for health inputs, including the utilization of health services (Strauss and Thomas 1995).

\subsection{Intrahousehold Education and Literacy Externalities}

As noted, the focus on maternal education as the primary variable of interest in the analysis of health service use and child health may be justified on the basis of a

\footnotetext{
${ }^{2}$ For reviews see Behrman and Deolalikar (1988), Schultz (1999) and Strauss and Thomas (1995; 1998).

${ }^{3}$ In these studies education is typically measured by years of schooling or highest grade attained. These are, however, likely to be poor proxies for educational achievement, which is the product of a complex combination of educational inputs, including, years in school, daily attendance, grade repetition, home support and tuition, household expenditure on schooling supplies, school characteristics, and so forth. A few studies that have tried to assess the relative importance of different dimensions of educational achievement (specific knowledge, cognitive skills, norms and values). Glewwe (1999) and Thomas, Strauss, and Henriques (1990) comprise important exceptions.

${ }^{4}$ The exception is breast-feeding, where better educated women are less likely to breast feed, and tend to breast feed for a shorter period (Cebu Study Team 1991; Wolfe and Behrman 1982).
} 
priori assumptions about gender differences in preferences, or about gender specificities in the knowledge and information conveyed by education. However, the sole focus on own education in the analysis of health care demand is at odds with evidence on more general intrahousehold education externalities.

The idea that the education or literacy of one individual can bring benefits for other individuals in his or her proximity - through assistance with administrative tasks or decisionmaking - is not new. The possibility of such externalities has been recognized and studied in a range of different areas, including agricultural innovation (Green, Rich and Nesman 1985), farm productivity (Foster and Rosenzweig 1996), labor earnings (Basu, Narayan, and Ravallion 2002), and child health (Gibson 1999). ${ }^{5}$ The possibility of literacy externalities has also given rise to a literature on how literacy ought to be measured (Basu and Foster 1998; Basu, Foster, and Subramanian. 2001; Subramanian 2001). Specifically, Basu and Foster (1998) propose that intrahousehold externalities from literacy should be taken into account in the measurement of literacy. In order to do so, they distinguish between isolated illiterates - illiterate individuals in households where no one is literate — and proximate illiterates, who live in households where at least one person is literate. On this basis, they put forward an alternative indicator, the effective literacy rate that takes this distinction into account. This is based on the idea that each proximate literate can be considered to have a level of literacy of $\alpha(0<\alpha<1)$, compared to 0 for isolated literates and 1 for literates. The effective literacy rate is simply the population mean of this "corrected" literacy variable.

The Basu and Foster (1998) framework provides a basis for the empirical analysis of literacy externalities. ${ }^{6}$ However, as they recognize, the basic framework abstracts from a number of issues. In particular, the externality may be both issue and person specific. In other words, the impact of another household member's literacy on behavior or outcomes may depend both on who holds the education and who is benefiting from the externality. This may, for example, be due to gender biases in the production of literacy or education externalities, such that the presence of a literate or educated woman in the household has a greater impact on the function of other household members than the presence of an educated or literate man. Moreover, Basu and Foster (1998) restrict attention to literacy. But educational achievement is likely to have an impact on behavior and outcomes beyond literacy. This then calls for a more general framework.

\section{Analytical Framework and Empirical Approach}

\subsection{Modeling Intrahousehold Education Externalities}

Basu and Foster (1998) propose a framework where every household, $h$, can be characterized by a literacy profile, $\mathbf{x}^{h}=\left(x_{1}^{h}, x_{2}^{h}, \ldots, x_{n}^{h}\right)$. According to the standard conception of literacy, $x_{i}^{h}=1$ if the individual is literate, and $x_{i}^{h}=0$ otherwise. In the presence of literacy externalities, however, $x_{i}^{h}=\alpha,(\alpha>0)$ for proximate literates-

\footnotetext{
${ }^{5}$ The focus on intrahousehold dynamics in health care choices also highlights the potential role education plays in changing the relative autonomy and bargaining power of different household members. This issue is not explored in the paper.

${ }^{6}$ For example, using a model of children's height-for-age in Papua New Guinea (PNG), Gibson (1999) finds an estimate of 0.76 for the intrahousehold externality from living in the same household as a literate individual $\alpha$.
} 
illiterate individuals living in the same household as a literate individual. ${ }^{7}$ In contrast to the case of literacy externalities, the analysis of education externalities is complicated by the fact that education, unlike literacy, is not a binary variable. As a consequence, the externality may be a function of the level of education, and may depend on the level of education of both the source and the recipient of the externality.

Following the general notation of Basu and Foster (1998), consider a household with the education profile $\mathbf{e}^{\mathbf{h}}=\left(e_{1}^{h}, e_{2}^{h}, \ldots, e_{n}^{h}\right)$, where we can think of $e_{i}^{h}$ as numbers of years of schooling, highest grade attained, or some other proxy for educational attainment of individual $i$. We denote the effective level of education of individual $i$ as

$$
\begin{gathered}
\bar{e}_{i}^{h}=f\left(e_{i}^{h}, \mathbf{e}_{-\mathbf{i}}^{\mathbf{h}} ; \boldsymbol{\theta}\right), \text { where } \\
\mathbf{e}_{-\mathbf{i}}^{\mathbf{h}} \equiv\left\{e_{k}^{h} \in \mathbf{e}^{\mathbf{h}}: \forall k \neq i\right\},
\end{gathered}
$$

and $\theta$ is some parameter vector. The effective level of education incorporates intrahousehold education externalities, thus representing the full set of information, values, and cognitive abilities that individual $i$ can bring to bear on any decisionmaking process. In other words, $\bar{e}_{i}^{h}$ is a function not only of the level of education of individual $i$, but also the education of other household members. ${ }^{8}$

It is difficult to represent specific hypotheses concerning education externalities on the basis of this general specification. Hence, in order to guide the empirical analysis we consider the case where $\bar{e}_{i}^{h}$ can be represented as a linear function of the level of education of the different household members. On this basis, we can represent both the absence of education externalities, the case of general education externalities, and three cases of specific education externalities.

(A) Education is a pure private good. It is possible to conceive of education, and the information, knowledge, and values that it conveys, as a bringing benefits solely to the educated individual. In other words, there are no intrahousehold externalities from education, and the decisions relating to health care are only influenced by the education of the individual making the choice. In this case,

$$
\bar{e}_{i}^{h}=e_{i}^{h} \forall i \in h .
$$

(B) General intrahousehold education externalities. There may be a general education externalities for $i$ from the education of other household members. These may, as noted, be due to complementarity effects, whereby the information or knowledge of other members of the household may fill gaps in the information or knowledge of individual $i$. Alternatively, these externalities may arise due to the dialectic nature of the decision process concerning health care, where different members are consulted and have an input in the decisionmaking. In both these cases, externalities may arise even if the other

\footnotetext{
${ }^{7}$ On this basis, the effective literacy rate is $r^{*}=(L+\alpha P) / N$, where $L$ is the number of literate individuals in the population, $P$ is the number of proximate literate individuals, and $N$ is the total population.

${ }^{8}$ Individuals outside the household that form part of an individual's social network may also influence his or her effective level of education. This possibility is not explored further here.
} 
household members have a lower level of education than $i$. With this general externality, the effective level of education of $i$ is

$$
\bar{e}_{i}^{h}=e_{i}^{h}+\sum_{-i} \alpha_{k} e_{k}^{h} .
$$

(C) Specific education externalities. There are also some more specific possibilities that are nested in this general framework.

(C1) There may be education externalities for $i$ from the education of $k$, where these are contingent on $k$ being the spouse or partner of $i$. This would be the case, for example, if education complementarities arise exclusively or primarily in the relationship between spouses. In this case, the effective level of education is

$$
\begin{gathered}
\bar{e}_{i}^{h}=e_{i}^{h}+\sum_{-i}\left(\alpha_{k}^{1} e_{k}^{h}+\alpha_{k}^{2} d_{\text {spouse }, k} e_{k}^{h}\right), \text { where } \\
d_{\text {spouse }, k}=\left\{\begin{array}{l}
1 \text { if } k \text { is } i^{\prime} \text { s spouse } \\
0 \text { otherwise }
\end{array}, k \in-\mathbf{i}, k \neq i .\right.
\end{gathered}
$$

(C2) There may be education externalities for $i$ from the education of $k$, where these are contingent on $k$ being a woman. This would be consistent with the case where education complementarities in relation to decisions about reproductive or child health arise exclusively or primarily in the relationship between women, such that,

$$
\begin{gathered}
\bar{e}_{i}^{h}=e_{i}^{h}+\sum_{-i}\left(\alpha_{k}^{1} e_{k}^{h}+\alpha_{k}^{2} d_{\text {woman }, k} e_{k}^{h}\right), \text { where } \\
d_{\text {woman }, k}=\left\{\begin{array}{l}
1 \text { if } k \text { is a woman } \\
0 \text { otherwise }
\end{array}, k \in-\mathbf{i}, k \neq i .\right.
\end{gathered}
$$

(C3) There may be education externalities for $i$ from the education of other household members, where these are contingent on $k$ has a higher level of education than $i$. This would be consistent with the case where the choice of individual $i$ is primarily a function of his or her education, but where it is possible to make use of the additional knowledge or information of another household member. In this case, the effective level of education is

$$
\begin{gathered}
\bar{e}_{i}^{h}=e_{i}^{h}+\sum_{-i}\left(\alpha_{k}^{1} e_{k}^{h}+\alpha_{k}^{2} d_{\text {higher }, k} e_{k}^{h}\right), \text { where } \\
d_{\text {higher }, k}=\left\{\begin{array}{l}
1 \text { if } s_{i}^{h}>s_{k}^{h} \\
0 \text { otherwise }
\end{array}, k \in-\mathbf{i}, k \neq i .\right.
\end{gathered}
$$

\subsection{Empirical Approach: Modeling, Estimation, and Hypothesis Testing}

In a static framework of health care demand (Gertler, Locay, and Sanderson 1987; Gertler and van der Gaag 1990), a woman's choice between use and nonuse of maternity and child health services can be cast in a simple random utility model. The utility of the two alternatives (service use $(s)$ and nonuse $(n s)$ ) are

$$
U^{s}=U\left(h_{s}, x_{s}, \varepsilon_{s} ; \boldsymbol{\varphi}_{s}\right) \text { and } U^{n s}=U\left(h_{n s}, x_{n s}, \varepsilon_{n s} ; \boldsymbol{\varphi}_{n s}\right),
$$


where, $h$ is health status, $x$ is a vector of nonhealth (residual) consumption, $\varepsilon$ is a random error term, and $\varphi$ is a parameter vector. Nonhealth consumption, $x$, is a function of exogenous income, $y$, the total cost of care (including both direct and indirect costs), $c$. Health status $\left(h_{s}\right.$ and $\left.h_{n s}\right)$, in turn, can be represented as

$$
h_{s}=h\left(\mathbf{z}, \mathbf{e} ; \boldsymbol{\beta}_{s}\right) \text { and } h_{n s}=h\left(\mathbf{z}, \mathbf{e} ; \boldsymbol{\beta}_{n s}\right) \text {, }
$$

where $\mathbf{z}$ is a vector of individual, household, community, and health care provider characteristics, $\mathbf{e}$ is a vector of variables that determine the effective level of education, and $\beta_{s, n s}$ are parameter vectors. The health care choice is represented by the indicator function

$$
S=1\left[U_{s}>U_{n s}\right]
$$

The essential feature of the model concerns the tradeoff between health and nonhealth consumption. This tradeoff arises as long as $x_{s}<x_{n s}$ and $h_{s}>h_{n s}$. In order to operationalize this general analytical framework, we must be more specific about functional form. Following the early literature on health care demand in developing countries (Akin and others 1984, 1986; Mwabu 1986), the empirical specification is based on a linear utility and health production function, such that

$$
\begin{gathered}
U^{s}=\varphi_{s 1} h_{s}+\varphi_{s 2} x_{s}+\varepsilon_{s} \text { and } U^{n s}=\varphi_{n s 1} h_{n s}+\varphi_{n s 2} x_{n s}+\varepsilon_{n s} \text {, and } \\
h_{s}=\boldsymbol{\beta}_{s}^{z \prime} \mathbf{z}+\boldsymbol{\beta}_{s}^{e^{\prime}} \mathbf{e} \text { and } h_{n s}=\boldsymbol{\beta}_{n s}^{z} \mathbf{z}+\boldsymbol{\beta}_{n s}^{e}{ }^{\prime} \mathbf{e} .{ }^{9}
\end{gathered}
$$

In line with the representation of education externalities set out above, the vector $\mathbf{e}$ is assumed to contain (a) the highest grade completed by the woman, (b) the highest grade completed by her spouse (if present), and (c) the highest grade completed by other members of the household (if present). In order to keep the empirical specification manageable, it is assumed that decisions relating to the use of health services can be influenced by the education of up to three other household members (Oth1, Oth2, and Oth3). ${ }^{10}$ To distinguish cases where a particular household member (spouse or "other") is not present from the case where he or she is present but does not have any formal education, the model includes dummy variables indicating who is present in the household. For "other" household members the model also includes an interaction term, where educational attainment is interacted with whether the person is a woman or not. This permits testing of whether the presence of educated women in the household has a greater impact on health care decisions than the presence of educated men. In summary,

\footnotetext{
${ }^{9}$ Gertler and van der Gaag (1990) and Dow (1996) have noted considerable weaknesses with this specification. In particular, it does not permit the price elasticity of demand to be a function of income. However, given the focus of this paper, the simpler specification is adequate.

${ }^{10}$ It is assumed that the educational attainment of other household members with the highest level of education is most likely to be important. In other words, the other household members are sorted by educational attainment, such that for all household members ( $>13$ years), Oth1Edu $\geq$ Oth2Edu $\geq$ $O t h 3 E d u \geq$ highest grade attained by any remaining household member.
} 


$$
\begin{aligned}
& \boldsymbol{\beta}_{s}^{e} \mathbf{e} \quad=\beta_{s 1}^{e} W o m E d u \\
& +\beta_{s 2}^{e} \text { Spouse }+\beta_{s 3}^{e} \text { SpouseEdu } \\
& +\beta_{s 4}^{e} \text { Oth } 1+\beta_{s 5}^{e} \text { Oth } 1 E d u+\beta_{s 6}^{e}(\text { Oth } 1 E d u \times \text { Female }) \\
& +\beta_{s 7}^{e} \text { Oth } 2+\beta_{s 8}^{e} \text { Oth } 2 E d u+\beta_{s 9}^{e}(\text { Oth } 2 E d u \times \text { Female } 2) \\
& +\beta_{s 10}^{e} \text { Oth } 3+\beta_{s 11}^{e} \text { Oth } 3 E d u+\beta_{s 12}^{e}(\text { Oth } 3 E d u \times \text { Female }) \\
& \text { Spouse } \quad=\left\{\begin{array}{l}
1 \text { if woman has a spouse that is living in the same household } \\
0 \text { otherwise }
\end{array}\right. \\
& \text { SpouseEdu }=\left\{\begin{array}{l}
0 \text { if } \text { Spouse }=0 \\
0 \text { if } \text { Spouse }=1 \text { and spouse has no education } \\
1-13 \text { (highest grade) } \text { if } \text { Spouse }=1 \text { and spouse has education }
\end{array}\right. \\
& \left.\begin{array}{l}
\text { Oth1 } \\
\text { Oth2 } \\
\text { Oth3 }
\end{array}\right\}=\left\{\begin{array}{l}
1 \text { if other person present in the household } \\
0 \text { otherwise }
\end{array}\right. \\
& \text { Oth } 1 E d u=\left\{\begin{array}{l}
0 \text { if } \text { Oth } 1=0 \\
0 \text { if } O t h 1=1 \text { but spouse has no education } \\
1-13 \text { (highest grade) if } \text { Oth } 1=1 \text { and he/she has education }
\end{array}\right. \\
& \text { (The variables } O t h 2 E d u \text { and } O t h 3 E d u \text { are similarly defined) } \\
& \text { Female } 1=\left\{\begin{array}{l}
1 \text { if } \text { Othl person is a woman } \\
0 \text { otherwise }
\end{array}\right. \\
& \text { (The variables Female } 2 \text { and Female } 3 \text { are similarly defined) }
\end{aligned}
$$

Finally, we assume that nonhealth consumption is a function of exogenous income and travel time, such that

$$
x_{s}=\gamma_{s 1} y-\gamma_{s 2} \text { Time and } x_{n s}=\gamma_{n s 1} y-\gamma_{n s 2} \text { Time } .
$$

Using the linear functions for $h$ and $x$ in the utility function, and with an appropriate reparametrization,

$$
U^{s}=U\left[\boldsymbol{\alpha}_{s}{ }^{\prime} \mathbf{w}+\varepsilon_{s}\right] \text { and } U^{n s}=U\left[\boldsymbol{\alpha}_{n s}{ }^{\prime} \mathbf{w}+\varepsilon_{n s}\right] \text {, where }
$$

$$
\mathbf{w}=\left[\begin{array}{c}
\mathbf{z} \\
\mathbf{e} \\
y \\
\text { Time } \\
\text { Time }^{2}
\end{array}\right] .
$$

is

On this basis, the probability that the woman uses the particular health service

$$
\operatorname{Pr}[S=1 \mid \mathbf{w}]=\operatorname{Pr}\left[U^{s}>U^{n s}\right]=\operatorname{Pr}\left[\left(\boldsymbol{\alpha}_{s}-\boldsymbol{\alpha}_{n s}\right) \mathbf{w}>\varepsilon_{n s}-\varepsilon_{s}\right]=\operatorname{Pr}[\mathbf{\alpha} \mathbf{w}>\varepsilon], \text { where }
$$




$$
\left(\boldsymbol{\alpha}=\boldsymbol{\alpha}_{s}-\boldsymbol{\alpha}_{n s} \text { and } \varepsilon=\varepsilon_{\mathrm{ns}}-\varepsilon_{\mathrm{s}}\right) .
$$

Under the assumption that $\varepsilon \sim \mathrm{N}(0,1)$,

$$
\operatorname{Pr}[S=1 \mid \mathbf{w}]=\operatorname{Pr}\left[\boldsymbol{\alpha}^{\prime} \mathbf{w}>\varepsilon\right]=\operatorname{Pr}\left[\boldsymbol{\alpha}^{\prime} \mathbf{w}<\varepsilon\right]=\Phi\left(\boldsymbol{\alpha}^{\prime} \mathbf{w}\right),
$$

where $\Phi$ is the standard normal distribution. This is the Probit model. Under appropriate regularity conditions, the parameter vector $\alpha$ can be estimated consistently using maximum likelihood techniques. This approach will further permit us to perform a series of hypothesis tests concerning single and joint restrictions on the coefficients of interest (summarized in Table 1). It is important to note that due to the inherent nonlinearities of the Probit model, these tests do not actually tell us whether a particular variable (or set of variables) has a significant impact on the probability of a woman seeking care. In other words, the estimated coefficients (and associated standard errors) concern the marginal effect of the independent variables on the index, $\alpha^{6} \mathbf{w}$, not the predicted probabilities. With this in mind, we also report the impact of the variables of interest on choice probabilities.

Table 1. Tests of Restrictions on the Estimated Coefficients

Provided that a woman has a spouse, and controlling for the educational attainment of other household members, the highest grade attained by the spouse has a significant marginal effect on women's health care decisions relating to maternity and child health services.

Provided that there are other members of the household over 13 years of age, and controlling for the educational attainment of the spouse, the highest grade attained by these household members have a significant marginal effect on women's health care health care decisions.

Provided that there are other members of the household over 13 years of age, and controlling for the educational attainment of the spouse and the "other" person in the household with the highest level of education, the grade attained by further household members has a significant marginal effect on women's health care health care decisions.

Provided that there are other individuals in the household over 13 years of age, the marginal effect of the highest grade attained on women's health care decisions is different depending on whether the other individuals are men or women (Oth1, Oth2 and Oth3).

Provided that there are other individuals in the household over 13 years of age, the marginal effect of the highest grade attained on women's health care decisions is different depending on whether the other individuals are men or women (Oth2 and Oth3).
SpouseEdu $=0$

\author{
Oth1Edu $=$ \\ Oth1Edu $+($ Oth1Edu $\times$ Female $)=$ \\ Oth2Edu $=$ \\ Oth2Edu $+($ Oth2Edu $\times$ Female $)=$ \\ Oth3Edu $=$ \\ Oth3Edu $+($ Oth3Edu $\times$ Female $)=0$ \\ Oth2Edu $=$ \\ Oth2Edu $+($ Oth2Edu $\times$ Female $)=$ \\ Oth3Edu $=$ \\ Oth3Edu $+($ Oth3Edu $\times$ Female $)=0$
}

Oth1Edu $\times$ Female $=$ Oth2Edu $\times$ Female $=$ Oth3Edu $\times$ Female $=0$

Oth2Edu $\times$ Female $=$ Oth3Edu $\times$ Female $=0$

Finally, in setting out alternative representations of the effective level of education, we proposed as one hypothesis that education externalities may arise only if the recipient of the externality has a lower level of education than the source. For women's health care choices, the education of others would, under this hypothesis, be more important if the level of education of the woman is low relative to the other household member. This possibility cannot be straightforwardly nested in the general empirical specification. Instead, we explore two related (although not necessarily consistent) ways of testing for this possibility. First, we test whether the coefficients 
on the education variables of interest, estimated over the set observations of women with no formal education, are the same as those estimated over the set of observations of women with some formal education. Second, we introduce an alternative specification of the education variables, where the level of education of the spouse and other household members is measured as the deviation from the woman's education (with a lower bound of zero), such that

$$
\begin{aligned}
\text { SpouseEdu' } & =\left\{\begin{array}{l}
0 \text { if } \text { Spouse }=0 \\
0 \text { if } \text { Spouse }=1 \text { and } \text { SpouseEdu } \leq \text { WomEdu } \\
\text { SpouseEdu }- \text { WomEdu otherwise }
\end{array}\right. \\
\text { Oth } 1 E d u^{\prime} & =\left\{\begin{array}{l}
0 \text { if } \text { Oth } 1=0 \\
0 \text { if } \text { Oth } 1=1 \text { and } \text { Oth } 1 E d u \leq W o m E d u \\
\text { Oth } 1 E d u-W o m E d u \text { otherwise }
\end{array}\right.
\end{aligned}
$$

(The variables $O t h 2 E d u, O t h 3 E d u$ and the relevant interaction variables are similarly defined)

As this specification cannot be represented as a restricted version of the original model, a test for non-nested models is performed.

\section{Data and Variables}

The empirical analysis is based on the 1996/97 Mozambique National Household Survey on Living Conditions (IAF). ${ }^{11}$ The survey was designed and implemented by the National Statistics Institute in Mozambique, and was conducted from February 1996 to April 1997. The sample was selected in three stages and is geographically stratified to ensure representativeness at both the provincial level and for urban/rural areas. The overall sample consists of 39,961 individuals in 7,920 households. ${ }^{12}$ For the analysis of maternity services, the relevant subsample consists of women between 12 and 49 years old who report having delivered a child in the 12 months preceding the survey (1,584 individuals in 1,509 households). Conversely, the analysis of childhood immunizations is based on the subsample of children between 12 and 48 months old (3,647 individuals in 3,046 households). ${ }^{13}$ However, for the decisions concerning immunizations, the education variable of primary interest relates to the mother or guardian. As some women have more than one child in the relevant age group, the subsample of mothers or guardians is smaller than the relevant subsample of children $(3,113$ individuals $){ }^{14}$

\footnotetext{
${ }^{11}$ Inquérito Nacional aos Agregados Familiares Sobre as Condições de Vida (IAF). Details concerning the survey can be found in Datt and others (2000) and Ministry of Planning and Finance (1998).

${ }^{12}$ Given that the research focuses on intrahousehold relationships, we opted to drop complete households when relevant data were missing for any of the individuals in the household. Approximately 6 percent of the original sample was dropped for this reason.

${ }^{13}$ The analysis focuses on whether children have received a complete set of immunizations. Children under 12 months are therefore excluded. Moreover, considering that some of the independent variables are time-variant, it is important to limit the time-gap between the measurement of the outcome and of the independent variables. With this in mind, children between 48 and 60 months old were excluded from the subsample.

${ }^{14}$ For most children, the mother is residing in the household. In cases where the mother is absent, the spouse of the head of household (or the head of household in the case of a female head) is assigned
} 


\section{Health Service Outcomes}

The three health service outcomes of interest in this paper are measured as binary variables, indicating whether a particular service was used or not. First, women (between the age of 12 and 49) who report having delivered a child in the last 12 months were asked whether they had attended any pregnancy controls, and whether they delivered their child in a hospital, health center, or maternity clinic. Second, in households with children under five years of age, respondents were asked about the number of doses of polio, DTP, measles, and BCG vaccinations that each child has received. A child is considered fully immunized if he/she has received three doses each of polio and DTP, and one dose each of measles and BCG. Subsample means for the relevant dependent variables are reported in Table 2.

\section{Table 2. Health Service Outcomes}

\begin{tabular}{|c|c|c|c|}
\hline \multirow[b]{2}{*}{ Variable } & \multirow{2}{*}{$\begin{array}{c}\text { Percent of } \\
\text { relevant } \\
\text { subsample }\end{array}$} & \multicolumn{2}{|c|}{ Subsample } \\
\hline & & $n$ & $\begin{array}{l}\text { Percent of } \\
\text { sample }\end{array}$ \\
\hline $\begin{array}{l}\text { Women had pregnancy control during last pregnancy (last } \\
12 \text { months) }\end{array}$ & 63.81 & 1,584 & 4.31 \\
\hline $\begin{array}{l}\text { Women delivered child in hospital or health center (last } 12 \\
\text { months) }\end{array}$ & 40.09 & 1,584 & 4.31 \\
\hline $\begin{array}{l}\text { Children more than } 12 \text { months but less than } 48 \text { months old } \\
\text { fully immunized }\end{array}$ & 45.41 & 3,647 & 9.18 \\
\hline$n=39,961$ & & & \\
\hline
\end{tabular}

\section{Characterizing Household Education and Structure}

Both female education and the education of other household members feature as key variables in the analysis. Education is measured by the highest grade of schooling completed. Under the current educational system in Mozambique, primary education is comprised of the first seven grades. It is subdivided in to two levels, with EP1 (Escola Primária 1) covering the first five years, and the EP2 (Escola Primária 2) covering the following two years. Many of the children who start primary education only complete one or two years before dropping out. Secondary education is offered in secondary, technical, and agricultural schools. It is only a small proportion of students from primary education go on to this level. Of these, a large proportion receive basic technical education lasting for three years. However, in order to enter tertiary education it is necessary to complete five full years of general secondary school. ${ }^{15}$

Data on educational attainment for the sample as a whole and for the relevant subsamples are summarized in Table 3. A large proportion of the Mozambican population has no formal education. This is particularly true for women. In 1997, less then 20 percent of the population had completed the first level of primary education (12.3 percent for women), and only a very small proportion had received any form of secondary education. The educational characteristics of the women in the respective sub-samples appear similar to that of women in the sample as whole (in the relevant

as the primary guardian. If such a person was not present in the household, the child was matched with the oldest female household member.

${ }^{15}$ This brief characterization of the Mozambican educational system refers to its current structure. Many of the individuals in the sample attended school during the colonial era, or prior to the educational reform that created the current system. Data on grades completed can therefore not be straightforwardly mapped onto levels of the educational system. 
age group). As expected, there is a strong relationship between the woman's education and the health service outcomes of interest (see Figure 1 in appendix).

Table 3. Educational Attainment

\begin{tabular}{|c|c|c|c|c|c|}
\hline $\begin{array}{l}\text { Highest grade } \\
\text { attained (percent) }\end{array}$ & $\begin{array}{c}\text { All } \\
\text { (aged 14-64) }\end{array}$ & $\begin{array}{c}\text { Men } \\
\text { (aged 14-64) }\end{array}$ & $\begin{array}{c}\text { Women } \\
\text { (aged 14-64) }\end{array}$ & $\begin{array}{c}\text { Women } \\
\text { (delivery) }\end{array}$ & $\begin{array}{c}\text { Women }^{* *} \\
\left.\text { (guardian }^{*}\right)\end{array}$ \\
\hline No education & 44.14 & 28.97 & 57.92 & 53.32 & 55.56 \\
\hline Year 1 & 7.44 & 7.05 & 7.79 & 7.84 & 7.96 \\
\hline Year 2 & 9.60 & 10.87 & 8.44 & 7.52 & 10.53 \\
\hline Year 3 & 9.51 & 12.39 & 6.90 & 7.75 & 6.25 \\
\hline Year 4 & 10.64 & 15.04 & 6.65 & 8.89 & 7.60 \\
\hline Year 5 & 6.72 & 8.45 & 5.14 & 6.63 & 5.05 \\
\hline Year 6 & 5.28 & 7.49 & 3.27 & 3.60 & 3.50 \\
\hline Year 7 & 2.86 & 4.09 & 1.74 & 2.25 & 1.43 \\
\hline Year 8 & 1.35 & 1.87 & 0.87 & 1.18 & 0.80 \\
\hline Year 9 & 1.20 & 1.70 & 0.75 & 0.68 & 0.89 \\
\hline Year 10 or higher & 1.26 & 2.07 & 0.50 & 0.36 & 0.46 \\
\hline$n$ & 22,670 & 10,685 & 11,985 & 1,584 & 3,113 \\
\hline
\end{tabular}

* Subsample1: Women who delivered a child in the last 12 months.

** Subsample 2: Mother or guardian of children aged 1-3.

However, the central question in this paper is whether the level of education of other household members also has an impact on outcomes (summary statistics of the relevant variables are provided in Table 4). Approximately 80 percent of the women in the respective samples have a spouse residing in the household. In the majority of these cases, the spouse has a higher level of education than the woman. The spouse is however not the only person that may influence health service outcomes. Indeed most women live in households with one or more other adult ( $>15$ years) person. The average level of education of these "other" individuals is lower than for the spouse, yet it is far from unusual that someone other than the woman or the spouse has the highest level of education in the household.

\section{Controls in the Analysis}

Five types of variables are included as controls in the analysis. ${ }^{16}$ First, we seek to control for key characteristics of the health care supply. Specifically, the analysis includes variables relating to travel time, the accessibility of primary health care providers (proxied by the transitability of roads and the regularity of public transport in the community), and the existence of a hospital in the district. Health care quality is proxied by the deviation of district-level spending from a norm based on infrastructure characteristics, staffing, and the activity level in district. Second, household level determinants include household size and two proxies for the economic situation of the household (per capita consumption and an indicator variable for whether anyone in the household has a profession). Third, some of the characteristics of the woman comprise important controls in the analysis, including her age, and variables indicating her relationship with the head of household, whether she is married (in part to control for cases where woman has a spouse that does not reside in the household), whether she working, and whether she has a profession (as proxies for economic independence). Fourth, for the analysis of child immunizations, two indicator variables for the child's relation to the head of household, and for

${ }^{16}$ All variables described fully in appendix Table A1, Table A2, and Table A3). 
whether he/she is the first child are included. Finally, the estimation uses provinciallevel fixed effects to control for unmeasured spatial differences, including the supply of health services and in norms and values.

Table 4. Educational Characteristics of Households

\begin{tabular}{lrr}
\hline & $\begin{array}{c}\text { Women } \\
\text { (delivery) }^{*}\end{array}$ & $\begin{array}{c}\text { Women } \\
\text { (guardian) }^{* *}\end{array}$ \\
\hline Highest grade attained by woman (mean) & 1.72 & 1.54 \\
Someone in household has higher level of education than woman (\%) & 66.17 & 65.86 \\
Spouse & & \\
Present: woman has spouse (\%) & 80.20 & 80.67 \\
Highest grade attained by spouse (mean) & 2.55 & 2.55 \\
Spouse has higher level of education than woman (\%) & 48.41 & 49.64 \\
Oth1: "Other" person with highest level of education & & \\
Present: someone other than spouse in household older than 15 & 55.96 & 60.37 \\
Highest grade attained (mean) & 1.73 & 1.80 \\
Other person has higher level of education than woman (\%) & 30.75 & 33.00 \\
Oth2: "Other" person with second highest level of education & & \\
Present (\%) & 38.09 & 39.12 \\
Highest grade attained (mean) & 0.86 & 0.87 \\
Other person has higher level of education than woman (\%) & 13.73 & 15.37 \\
Oth3: "Other" person with third highest level of education & & \\
Present (\%) & 23.79 & 24.10 \\
Highest grade attained (mean) & 0.43 & 0.41 \\
Other person has higher level of education than woman (\%) & 5.55 & 6.66 \\
$N \quad$ & 1,584 & 3,113 \\
\hline
\end{tabular}

* Subsample1: Women who delivered a child in the last 12 months.

** Subsample 2: Mother or guardian of children aged 1-3.

\section{Findings}

This section summarizes the results from the empirical analysis. ${ }^{17}$ Although the issue of primary interest concerns the effect of education on health care choices, we begin by summarizing the findings for the controls in the analysis (full Probit results are reported in appendix Table A4).

As expected, physical inaccessibility to health care providers is an important deterrent. This is reflected not only in significant coefficients on travel time, but also in the importance of transport and access routes. Other aspects of the health facility infrastructure seems less important. In particular, it is noteworthy that neither the presence of a hospital in the district nor the proxy for health care quality has a significant impact on utilization. Economic status, as measured by per capita household consumption, does not have a significant impact on utilization. However, other variables relating to economic status, including whether there is a person in the household that has a profession and whether the woman in question has a profession are significant for at least one of the health services. This effect may, however, capture differences in health-related norms and values between professionals and nonprofessionals, rather than the effect of the household's economic situation in a more narrow sense. The results further suggest that household structure and relations may play a role in decisions relating to health care. In the case of maternity care, being the daughter of the head appears to convey some privileges in terms of health service utilization. Similarly, children of the head of the household also appears to be

\footnotetext{
${ }^{17}$ Full results from the estimation and the hypothesis tests are reported in the appendix.
} 
more likely to be immunized. There is also some evidence of a family size and birth order effect. Finally, service use appears to be systematically higher in urban areas, even after controlling for measured differences in access, quality, and household characteristics. Similarly, there are some important interprovincial differences that are not captured by the variation in the set of explanatory variables. ${ }^{18}$ Both the effect of living in urban areas and the significant provincial fixed effects suggest that there are important unmeasured determinants of health service use. This may relate to unmeasured aspects of access, or spatial differences in health-related information, norms, and values.

Turning to the impact of education on health care choices, we begin by considering the results based on the original specification of the education variable (education measured as highest grade attained for all household members). In particular, we consider the five single and joint hypotheses set out in Table 1 (test statistics are reported in full in Table 5). First, provided that the woman has a spouse residing in the household, his level of education appears to have a significant impact on some heath care decisions. Specifically, the marginal effect of the highest grade attained by the spouse is positive and significant in the Probit analysis of the woman's decision to attend a pregnancy control and to immunize her child. Spousal education is, however, not a significant determinant in the woman's choice of where to deliver her child. Second, with the exception of the decision to attend a pregnancy control, we can reject the hypothesis that the education of other household members does not have an impact on decision relating to maternal and child health. Third, we can also reject the hypothesis that the education of others matters beyond the level of education attained by the "other" household member with the highest level of education. In other words, the marginal effects of highest grade attained for Oth2 and Oth 3 are not jointly significant. Finally, under the current specification, there is no statistically significant evidence that the impact of others' education is different depending on whether that person is a man or a woman. This is the case whether we consider only Oth1, or joint hypotheses.

These findings suggest that the education of both the woman's spouse and other members of the household are important factors in decisions concerning maternal and child health care. However, as noted, the estimated coefficients are not very informative about the quantitative impact on estimated choice probabilities. In general both choice probabilities, the marginal effect of specific variables on the choice probabilities and the standard errors of predicted probabilities, depend on the full vector of independent variables $(\mathbf{w})$. We assess the impact of the variables of interest on predicted choice probabilities at the means of the remaining independent variables, thereby controlling for the confounding effects of covariates. ${ }^{19} \mathrm{In}$ particular, for each of the education variables (own education, spousal education, and the education of the other household member with the highest level of education) we consider how choice probabilities change as the highest grade completed changes

\footnotetext{
${ }^{18}$ In broad terms, individuals in the southern provinces (Maputo City, Maputo Province, Gaza, Inhambane), and to some extent Tete, are more likely to use maternity health services and to immunize their children.

${ }^{19}$ Both the marginal effect of the variable of interest and the standard error of predicted choice probabilities can vary considerably with the vector of independent variables.
} 
from no education to completed EP1 (grade 5), while holding the other education variables at their mean (see Table 6). ${ }^{20}$

Table 5. Test Statistics for Estimated Coefficients

\begin{tabular}{|c|c|c|c|}
\hline$H_{0}$ & \multicolumn{3}{|c|}{ Prob. $\mathrm{H}_{0}$ is true (Chi2) } \\
\hline SpouseEdu $=0$ & 0.071 & 0.627 & 0.005 \\
\hline $\begin{array}{l}\text { Oth1Edu }= \\
\text { Oth1Edu }+(\text { Oth1Edu } \times \text { Female })= \\
\text { Oth2Edu }= \\
\text { Oth2Edu }+(\text { Oth2Edu } \times \text { Female })= \\
\text { Oth3Edu }= \\
\text { Oth3Edu }+(\text { Oth3Edu } \times \text { Female })=0\end{array}$ & 0.146 & 0.001 & 0.007 \\
\hline $\begin{array}{l}\text { Oth2Edu }= \\
\text { Oth2Edu }+(\text { Oth2Edu } \times \text { Female })= \\
\text { Oth3Edu }= \\
\text { Oth3Edu }+(\text { Oth3Edu } \times \text { Female })=0\end{array}$ & 0.934 & 0.351 & 0.578 \\
\hline $\begin{array}{l}\text { Oth1Edu } \times \text { Female }= \\
\text { Oth2Edu } \times \text { Female }= \\
\text { Oth3Edu } \times \text { Female }=0\end{array}$ & 0.902 & 0.258 & 0.315 \\
\hline $\begin{array}{l}\text { Oth2Edu } \times \text { Female }= \\
\text { Oth3Edu } \times \text { Female }=0\end{array}$ & 0.753 & 0.424 & 0.526 \\
\hline
\end{tabular}

Statistics from Wald tests of single and joint hypotheses.

As expected, the level of education of the woman has a big impact on the probability of using maternal and child health services. At the means of the other variables, there is a difference of approximately 0.2 in the predicted probabilities as the woman's education increases from no education to completed primary. The high level of significance of own education is reflected in fairly narrow confidence intervals. Considering the case of women with an average level of education, spousal education has a fairly small impact on predicted probabilities, particularly in the case of institutional delivery. In contrast, the marginal effect of increasing education of other household members is notable. This is particularly the case for maternity care, where the probability of service use increases with 0.16 and 0.27 , respectively, for pregnancy control and institutional delivery as the level of education of Othl goes from 0 to 5 .

${ }^{20}$ The impact of the respective education variables on predicted probabilities is described more fully in the appendix (Figure 2, Figure 3, and Figure 4). These graphs also illustrate that the potential importance of the indicator variables for spouse and other household members. The indicator variables permit the effect of the spouse or other household member not being present to differ from the effect of that person having no education. In some cases this distinction appears to be important. 
Table 6. Predicted Probabilities (with confidence intervals)

\begin{tabular}{|c|c|c|c|c|}
\hline & \multicolumn{2}{|c|}{ Relevant education variable $=0$} & \multicolumn{2}{|c|}{ Relevant education variable $=5$} \\
\hline & $\begin{array}{l}\text { Predicted } \\
\text { probability }\end{array}$ & $\mathrm{Cl}$ & $\begin{array}{l}\text { Predicted } \\
\text { probability }\end{array}$ & $\mathrm{Cl}$ \\
\hline \multicolumn{5}{|l|}{ Mother's education ${ }^{*}$} \\
\hline Pregnancy control & 0.60 & $(0.50,0.70)$ & 0.80 & $(0.71,0.88)$ \\
\hline Institutional delivery & 0.34 & $(0.26,0.42)$ & 0.54 & $(0.42,0.66)$ \\
\hline Immunization & 0.42 & $(0.34,0.49)$ & 0.56 & $(0.48,0.64)$ \\
\hline \multicolumn{5}{|l|}{ Education of spouse ${ }^{* *}$} \\
\hline Pregnancy control & 0.64 & $(0.54,0.74)$ & 0.73 & $(0.66,0.79)$ \\
\hline Institutional delivery & 0.40 & $(0.29,0.51)$ & 0.43 & $(0.37,0.50)$ \\
\hline Immunization & 0.40 & $(0.33,0.47)$ & 0.50 & $(0.44,0.55)$ \\
\hline \multicolumn{5}{|l|}{ Education of other $^{* \star *}$} \\
\hline Pregnancy control & 0.62 & $(0.50,0.72)$ & 0.78 & $(0.65,0.88)$ \\
\hline Institutional delivery & 0.31 & $(0.23,0.40)$ & 0.58 & $(0.44,0.70)$ \\
\hline Immunization & 0.43 & $(0.35,0.52)$ & 0.52 & $(0.44,0.61)$ \\
\hline
\end{tabular}

Finally, we turn to the question of specification. So far, we have assumed that the impact of education can be represented as a weighted sum of the education of different household members. An alternative specification, where the education of the spouse and other household members is measured as the deviation from the woman's education, may, however, be more appropriate. In order to address this question, the same model was estimated under this alternative specification. ${ }^{21}$ The estimated coefficients on the controls in the analysis are broadly unchanged. There are, however, some changes in the coefficients on the education variables of interest. In particular, the coefficient on the woman's own education increases, while the coefficients on spousal education and the education of the other person in the household with highest education increase slightly, or are broadly unchanged. Of course, spousal and "other" education is now measured as the deviation from the woman's education. As a consequence, the variables will tend to take a lower value, and in cases where the woman has some education, the impact of spousal and "other" education on predicted choice probabilities may be lower than in the original specification even though the coefficients are higher. Notwithstanding these changes, the broad conclusions concerning the hypotheses of interest continue to hold. In other words, even under this alternative specification, there is a significant marginal effect of spousal education on the probability of attending pregnancy control and child immunization (provided the spouse has a higher level of education than the woman). Similarly, the hypothesis that the education of other household members has a significant impact on health care choices (institutional delivery and child immunizations) cannot be rejected. However, as before, the effect is confined to the person with the highest level of education.

Although it is comforting that the main conclusions from the analysis are robust, it is natural to ask which specification is more appropriate. We address this

\footnotetext{
${ }^{21}$ Probit results for this alternative specification are reported in appendix Table A5; test statistics for the respective hypotheses concerning the coefficients of interest are reported in appendix Table A6.
} 
question in two ways. The first approach is based on testing whether the coefficients on the education variables of interest estimated over the subsample of women with no education are different from those estimated over the subsample of women with some education. $^{22}$ Although there is some ambiguity, the test statistics (Table A7) do not permit us to reject the hypothesis that the coefficients are the same across the subsamples (the hypothesis can be rejected only for spousal education in the case of child immunizations). Second, following Davidson and MacKinnon (1993), we also explore a more direct approach to test for the appropriateness of an alternative specification with a rival set of conditioning variables. The test asks whether there is any statistically significant evidence of departure from the null hypothesis in the direction of an alternative hypothesis. The results provide evidence in favor of the alternative specification in the case of pregnancy control, but not for the other health care choices (Table A8). In summary, the specification tests are inconclusive. They suggest that the rival specification of the relevant education variable may be more appropriate for some education variables, or in explaining some choices. There is, however, no basis for unambiguously favoring one specification over the other.

\section{Summary and Conclusion}

This paper has focused on the role of intrahousehold education externalities in health care choices. Its central premise is that health service use is determined not solely by an individual's own education, but rather by some notion of effective education, which incorporates the educational attainment of other household members. The paper sets out a general framework for representing education externalities and proposes a number of specific hypotheses concerning the way in which the education of different household members impacts on health care choices. These hypotheses were tested on data from Mozambique, focusing on maternity services and child immunizations. We can draw five major conclusions from the analysis.

First, while own/maternal education seems to be the education variable of primary importance for the health care choices under consideration, the education of other household members does have a significant and sometimes large effect. Importantly, it is not only the education of the spouse that matters, but also the education of other individuals residing in the household. Indeed, the marginal effect of education is greater for the nonspouse household member with the highest level of education than for the spouse. These findings appear robust to the how the education variable is specified. Second, the analysis suggests that while the education of the person (nonspouse) in the household with the highest-level education is important, the level of education of additional household members does not have an impact on health care choices. Third, the data provide no evidence of a gender difference in education externalities. In other words, the impact of the education of nonspouse household members on health care decisions seems to be the same regardless of whether they are men or women. Fourth, we examine the merits of two alternative representations of the education externality. In the original representation, education is measured as the highest grade completed. In the alternative specification, the educational attainment of other household members is measured as the deviation from

\footnotetext{
${ }^{22}$ This is done by testing restrictions in a model estimated over both subsamples, but including a set of independent variables constructed by interacting all the original variables (including the constant) with a subsample dummy variable.
} 
the woman's education. We are unable to conclude unambiguously in favor of one specification over the other. Finally, although the analysis highlights the importance of both education (broadly conceived) and a number of other explanatory variables in understanding health care choices, spatial fixed effects remain highly significant. Important questions hence remain about why health service indicators differ so markedly across provinces and urban/rural areas in Mozambique.

The analysis leaves a number of issues unresolved, thus pointing the direction for future research on this issue. The most obvious point to note is that although we have established the presence of education externalities, we have not shed much light on the channels by which these effects arise. In part, this is due to the use of a composite variable (highest grade attained) to proxy for the complex set of values, norms, information, and cognitive abilities that ultimately determine behavior. The disentangling of the relative importance of norms, values, and beliefs on health care choices (and the role of education in shaping these individual attributes) is clearly an important research agenda. The focus on intrahousehold dynamics in health care choices also highlights the potential role that education plays in changing the relative autonomy and bargaining power of different household members. Although this issue is left unexplored in the paper, it deserves attention in future research. 


\section{Appendix}

\section{Table A1. Description of variables}

\begin{tabular}{|c|c|}
\hline Dlvry_cont & $\begin{array}{l}\text { Indicator variable for whether woman who delivered child in last } 12 \text { moths attended a pregnancy } \\
\text { control at some point during her pregnancy }\end{array}$ \\
\hline Dlvry_inst & $\begin{array}{l}\text { Indicator variable for whether woman who delivered child in last } 12 \text { moths did so with medical } \\
\text { supervision in a health facility }\end{array}$ \\
\hline Vacc_comp & $\begin{array}{l}\text { Indicator variable for whether child (older than } 12 \text { months but younger than } 5 \text { years) has received a } \\
\text { complete set of immunizations }\end{array}$ \\
\hline Time & Travel time in minutes from village to closest health centre or health post \\
\hline Time_sq & Travel time squared \\
\hline Inaccess & $\begin{array}{l}\text { Indicator variable for whether the community is inaccessible. A community is considered inaccessible } \\
\text { if (i) road to community is not passable throughout the year, and (ii) there is no regular collective } \\
\text { transport to and from the community. }\end{array}$ \\
\hline PubSpend & $\begin{array}{l}\text { District-level proxy for health care quality: deviation from norm on public spending on health, where } \\
\text { norm is based on infrastructure, staffing, and activity level in district. }\end{array}$ \\
\hline Hospital & Indicator variable for whether there is a hospital (central, provincial, general, or rural) in the district. \\
\hline Urban & Indicator variable for whether the household is residing in an urban area \\
\hline Income & $\begin{array}{l}\text { Indicator for socioeconomic status, measured by per capital household consumption, where } \\
\text { consumption has been deflated by a spatial price index. }\end{array}$ \\
\hline Prof_in_HH & Indicator variable for whether someone in the household has a profession. \\
\hline HH_size & Numer of household members \\
\hline Age & Age of woman \\
\hline Age_sq & Age of woman squared \\
\hline Daughter & Indicator variable for whether the woman is the daughter of the head of household \\
\hline Married & Indicator variable for whether the woman is married \\
\hline Wom_works & Indicator variable for whether the woman is currently working \\
\hline Wom_prof & Indicator variable for whether the woman has a profession \\
\hline Child_of_head & Indicator variable for whether the child (in case of immunizations) is a child of the head of household \\
\hline First_child & Indicator variable for whether the child (in case of immunizations) is the first child of woman \\
\hline WomEdu & $\begin{array}{l}\text { Highest grade of schooling completed by woman (mother or guardian of child in case of } \\
\text { immunizations). }\end{array}$ \\
\hline Spouse & Indicator variable for whether the woman has a spouse that is residing in the household \\
\hline SpouseEdu & $\begin{array}{l}\text { Highest grade of schooling completed by spouse (equal to zero of no spouse or spouse not residing } \\
\text { in household) }\end{array}$ \\
\hline Oth1 & Indicator variable for whether there is another person ( $>13$ years) residing in the household \\
\hline Oth1Edu & $\begin{array}{l}\text { Highest grade of schooling completed by the "other" person with the highest level of schooling (equal } \\
\text { to zero if there are no "other" persons residing in the household }\end{array}$ \\
\hline Oth1Edu x Female & Interaction variable: Oth1Edu interacted with whether Oth1 is a woman \\
\hline Oth2 & $\begin{array}{l}\text { Indicator variable for whether there is another person (>13 years) residing in the household (except } \\
\text { for Oth1) }\end{array}$ \\
\hline Oth2Edu & $\begin{array}{l}\text { Highest grade of schooling completed by the "other" person with the highest level of schooling (equal } \\
\text { to zero if there are no "other" persons residing in the household aside from Oth1 }\end{array}$ \\
\hline Oth2Edu x Female & Interaction variable: Oth2Edu interacted with whether Oth2 is a woman \\
\hline Oth3 & $\begin{array}{l}\text { Indicator variable for whether there is another person (>13 years) residing in the household (except } \\
\text { for Oth1 and Oth2) }\end{array}$ \\
\hline Oth3Edu & $\begin{array}{l}\text { Highest grade of schooling completed by the "other" person with the highest level of schooling (equal } \\
\text { to zero if there are no "other" persons residing in the household aside from Oth1 and Oth2 }\end{array}$ \\
\hline Oth3Edu x Female & Interaction variable: Oth3Edu interacted with whether Oth3 is a woman \\
\hline
\end{tabular}


Table A2. Variable Values (maternity care subsample)

\begin{tabular}{|c|c|c|c|c|c|c|c|}
\hline Variable & Mean & S.D. & Min & 0.25 & $M d n$ & 0.75 & Max \\
\hline Time & 137.21 & 246.20 & 3.00 & 15.00 & 60.00 & 150.00 & $4,320.00$ \\
\hline Time_sq & $79,400.12$ & $540,118.99$ & 9.00 & 225.00 & $3,600.00$ & $22,500.00$ & $18,662,400.00$ \\
\hline Inaccess & 0.26 & 0.44 & 0.00 & 0.00 & 0.00 & 1.00 & 1.00 \\
\hline PubSpend & -0.03 & 0.31 & -1.45 & -0.15 & -0.03 & 0.16 & 0.53 \\
\hline Hospital & 0.43 & 0.50 & 0.00 & 0.00 & 0.00 & 1.00 & 1.00 \\
\hline Urban & 0.20 & 0.40 & 0.00 & 0.00 & 0.00 & 0.00 & 1.00 \\
\hline Income & 8.24 & 0.63 & 5.93 & 7.85 & 8.24 & 8.65 & 10.75 \\
\hline Prof_in_HH & 0.21 & 0.41 & 0.00 & 0.00 & 0.00 & 0.00 & 1.00 \\
\hline HH_size & 6.17 & 2.93 & 1.00 & 4.00 & 6.00 & 8.00 & 23.00 \\
\hline Age & 26.83 & 7.47 & 13.00 & 21.00 & 25.00 & 31.00 & 60.00 \\
\hline Age_sq & 775.43 & 450.64 & 169.00 & 441.00 & 625.00 & 961.00 & $3,600.00$ \\
\hline Daughter & 0.11 & 0.32 & 0.00 & 0.00 & 0.00 & 0.00 & 1.00 \\
\hline Married & 0.87 & 0.33 & 0.00 & 1.00 & 1.00 & 1.00 & 1.00 \\
\hline Wom_works & 0.52 & 0.50 & 0.00 & 0.00 & 1.00 & 1.00 & 1.00 \\
\hline Wom_prof & 0.03 & 0.17 & 0.00 & 0.00 & 0.00 & 0.00 & 1.00 \\
\hline WomEdu & 1.12 & 1.37 & 0.00 & 0.00 & 0.00 & 2.16 & 5.01 \\
\hline Spouse & 0.80 & 0.40 & 0.00 & 1.00 & 1.00 & 1.00 & 1.00 \\
\hline SpouseEdu & 1.61 & 1.51 & 0.00 & 0.00 & 1.63 & 2.64 & 7.27 \\
\hline SpouseEdu' & 1.04 & 1.21 & 0.00 & 0.00 & 0.00 & 2.16 & 5.69 \\
\hline Oth1 & 0.56 & 0.50 & 0.00 & 0.00 & 1.00 & 1.00 & 1.00 \\
\hline Oth1Edu & 1.10 & 1.46 & 0.00 & 0.00 & 0.00 & 2.16 & 6.02 \\
\hline Oth1Edu' & 0.64 & 1.07 & 0.00 & 0.00 & 0.00 & 1.00 & 5.01 \\
\hline Oth1Edu x Female & 0.37 & 0.98 & 0.00 & 0.00 & 0.00 & 0.00 & 5.69 \\
\hline Oth1Edu x Female' & 0.18 & 0.61 & 0.00 & 0.00 & 0.00 & 0.00 & 5.01 \\
\hline Oth2 & 0.38 & 0.49 & 0.00 & 0.00 & 0.00 & 1.00 & 1.00 \\
\hline Oth2Edu & 0.57 & 1.11 & 0.00 & 0.00 & 0.00 & 0.00 & 5.69 \\
\hline Oth2Edu' & 0.26 & 0.71 & 0.00 & 0.00 & 0.00 & 0.00 & 4.29 \\
\hline Oth2Edu $x$ Female & 0.27 & 0.83 & 0.00 & 0.00 & 0.00 & 0.00 & 5.01 \\
\hline Oth2Edu x Female' & 0.11 & 0.47 & 0.00 & 0.00 & 0.00 & 0.00 & 3.91 \\
\hline Oth3 & 0.24 & 0.43 & 0.00 & 0.00 & 0.00 & 0.00 & 1.00 \\
\hline Oth3Edu & 0.29 & 0.82 & 0.00 & 0.00 & 0.00 & 0.00 & 5.01 \\
\hline Oth3Edu' & 0.10 & 0.46 & 0.00 & 0.00 & 0.00 & 0.00 & 4.29 \\
\hline Oth3Edu x Female & 0.14 & 0.59 & 0.00 & 0.00 & 0.00 & 0.00 & 5.01 \\
\hline Oth3Edu x Female' & 0.04 & 0.29 & 0.00 & 0.00 & 0.00 & 0.00 & 3.51 \\
\hline $\begin{array}{l}\text { Provin=Cabo } \\
\text { Delgado }\end{array}$ & 0.08 & 0.27 & 0.00 & 0.00 & 0.00 & 0.00 & 1.00 \\
\hline Provin=Nampula & 0.20 & 0.40 & 0.00 & 0.00 & 0.00 & 0.00 & 1.00 \\
\hline Provin=Zambezia & 0.23 & 0.42 & 0.00 & 0.00 & 0.00 & 0.00 & 1.00 \\
\hline Provin=Tete & 0.08 & 0.28 & 0.00 & 0.00 & 0.00 & 0.00 & 1.00 \\
\hline Provin=Manica & 0.07 & 0.26 & 0.00 & 0.00 & 0.00 & 0.00 & 1.00 \\
\hline Provin=Sofala & 0.08 & 0.27 & 0.00 & 0.00 & 0.00 & 0.00 & 1.00 \\
\hline Provin=Inhambane & 0.07 & 0.25 & 0.00 & 0.00 & 0.00 & 0.00 & 1.00 \\
\hline Provin=Gaza & 0.05 & 0.23 & 0.00 & 0.00 & 0.00 & 0.00 & 1.00 \\
\hline Provin=Maputo & 0.04 & 0.20 & 0.00 & 0.00 & 0.00 & 0.00 & 1.00 \\
\hline $\begin{array}{l}\text { Provin=Maputo } \\
\text { Cidade } \\
N=1,584\end{array}$ & 0.05 & 0.23 & 0.00 & 0.00 & 0.00 & 0.00 & 1.00 \\
\hline
\end{tabular}


Table A3. Variable Values (immunization sub-sample)

\begin{tabular}{|c|c|c|c|c|c|c|c|}
\hline Variable & Mean & S.D. & Min & 0.25 & Mdn & 0.75 & Max \\
\hline Time & 134.14 & 248.33 & 3.00 & 15.00 & 45.00 & 150.00 & $4,320.00$ \\
\hline Time_sq & $79,642.89$ & $546,023.68$ & 9.00 & 225.00 & $2,025.00$ & $22,500.00$ & $18,662,400.00$ \\
\hline Inaccess & 0.24 & 0.43 & 0.00 & 0.00 & 0.00 & 0.00 & 1.00 \\
\hline PubSpend & -0.03 & 0.32 & -1.45 & -0.15 & -0.03 & 0.16 & 0.53 \\
\hline Hospital & 0.47 & 0.50 & 0.00 & 0.00 & 0.00 & 1.00 & 1.00 \\
\hline Urban & 0.21 & 0.41 & 0.00 & 0.00 & 0.00 & 0.00 & 1.00 \\
\hline Income & 8.24 & 0.66 & 5.70 & 7.83 & 8.21 & 8.63 & 11.37 \\
\hline Prof_in_HH & 0.22 & 0.42 & 0.00 & 0.00 & 0.00 & 0.00 & 1.00 \\
\hline HH_size & 6.33 & 2.64 & 2.00 & 4.00 & 6.00 & 8.00 & 23.00 \\
\hline Age & 29.77 & 8.77 & 8.00 & 23.00 & 28.00 & 35.00 & 98.00 \\
\hline Age_sq & 963.14 & 625.58 & 64.00 & 529.00 & 784.00 & $1,225.00$ & $9,604.00$ \\
\hline Married & 0.25 & 0.43 & 0.00 & 0.00 & 0.00 & 0.00 & 1.00 \\
\hline Wom_works & 0.53 & 0.50 & 0.00 & 0.00 & 1.00 & 1.00 & 1.00 \\
\hline Wom_prof & 0.03 & 0.16 & 0.00 & 0.00 & 0.00 & 0.00 & 1.00 \\
\hline Child_of_head & 0.83 & 0.38 & 0.00 & 1.00 & 1.00 & 1.00 & 1.00 \\
\hline First_child & 0.24 & 0.42 & 0.00 & 0.00 & 0.00 & 0.00 & 1.00 \\
\hline WomEdu & 1.02 & 1.31 & 0.00 & 0.00 & 0.00 & 2.16 & 5.01 \\
\hline Spouse & 0.80 & 0.40 & 0.00 & 1.00 & 1.00 & 1.00 & 1.00 \\
\hline SpouseEdu & 1.59 & 1.53 & 0.00 & 0.00 & 1.63 & 2.64 & 8.43 \\
\hline SpouseEdu' & 1.06 & 1.22 & 0.00 & 0.00 & 0.00 & 2.16 & 5.69 \\
\hline Oth1 & 0.62 & 0.49 & 0.00 & 0.00 & 1.00 & 1.00 & 1.00 \\
\hline Oth1Edu & 1.16 & 1.48 & 0.00 & 0.00 & 0.00 & 2.64 & 7.27 \\
\hline Oth1Edu' & 0.73 & 1.16 & 0.00 & 0.00 & 0.00 & 1.63 & 6.02 \\
\hline Oth1Edu x Female & 0.42 & 1.00 & 0.00 & 0.00 & 0.00 & 0.00 & 5.69 \\
\hline $\begin{array}{l}\text { Oth1Edu x } \\
\text { Female' }\end{array}$ & 0.24 & 0.71 & 0.00 & 0.00 & 0.00 & 0.00 & 4.66 \\
\hline Oth2 & 0.40 & 0.49 & 0.00 & 0.00 & 0.00 & 1.00 & 1.00 \\
\hline Oth2Edu & 0.59 & 1.13 & 0.00 & 0.00 & 0.00 & 0.00 & 5.69 \\
\hline Oth2Edu' & 0.32 & 0.80 & 0.00 & 0.00 & 0.00 & 0.00 & 4.29 \\
\hline Oth2Edu x Female & 0.26 & 0.81 & 0.00 & 0.00 & 0.00 & 0.00 & 5.69 \\
\hline $\begin{array}{l}\text { Oth2Edu } x \\
\text { Female' }\end{array}$ & 0.13 & 0.52 & 0.00 & 0.00 & 0.00 & 0.00 & 3.91 \\
\hline Oth3 & 0.25 & 0.43 & 0.00 & 0.00 & 0.00 & 0.00 & 1.00 \\
\hline Oth3Edu & 0.29 & 0.82 & 0.00 & 0.00 & 0.00 & 0.00 & 5.36 \\
\hline Oth3Edu' & 0.13 & 0.53 & 0.00 & 0.00 & 0.00 & 0.00 & 3.91 \\
\hline Oth3Edu x Female & 0.14 & 0.60 & 0.00 & 0.00 & 0.00 & 0.00 & 5.36 \\
\hline $\begin{array}{l}\text { Oth3Edu x } \\
\text { Female' }\end{array}$ & 0.06 & 0.36 & 0.00 & 0.00 & 0.00 & 0.00 & 3.91 \\
\hline $\begin{array}{l}\text { Provin=Cabo } \\
\text { Delgado }\end{array}$ & 0.08 & 0.27 & 0.00 & 0.00 & 0.00 & 0.00 & 1.00 \\
\hline Provin=Nampula & 0.19 & 0.39 & 0.00 & 0.00 & 0.00 & 0.00 & 1.00 \\
\hline Provin=Zambezia & 0.21 & 0.41 & 0.00 & 0.00 & 0.00 & 0.00 & 1.00 \\
\hline Provin=Tete & 0.08 & 0.27 & 0.00 & 0.00 & 0.00 & 0.00 & 1.00 \\
\hline Provin=Manica & 0.07 & 0.26 & 0.00 & 0.00 & 0.00 & 0.00 & 1.00 \\
\hline Provin=Sofala & 0.09 & 0.29 & 0.00 & 0.00 & 0.00 & 0.00 & 1.00 \\
\hline Provin=Inhambane & 0.07 & 0.25 & 0.00 & 0.00 & 0.00 & 0.00 & 1.00 \\
\hline Provin=Gaza & 0.06 & 0.23 & 0.00 & 0.00 & 0.00 & 0.00 & 1.00 \\
\hline Provin=Maputo & 0.05 & 0.22 & 0.00 & 0.00 & 0.00 & 0.00 & 1.00 \\
\hline $\begin{array}{l}\text { Provin=Maputo } \\
\text { Cidade } \\
N=3,647\end{array}$ & 0.05 & 0.22 & 0.00 & 0.00 & 0.00 & 0.00 & 1.00 \\
\hline
\end{tabular}


Table A4. Probit Results (education as highest grade attained)

\begin{tabular}{|c|c|c|c|c|c|c|}
\hline & \multicolumn{2}{|c|}{ Pregnancy control } & \multicolumn{2}{|c|}{ Institutional delivery } & \multicolumn{2}{|c|}{ Complete immunizations } \\
\hline & coeff. & z-values & coeff. & z-values & coeff. & z-values \\
\hline Time & -0.002 & {$[4.19]^{* \star}$} & -0.002 & {$[3.66]^{* *}$} & -0.001 & {$[3.45]^{\star *}$} \\
\hline Time_sq & 0.000 & {$[3.18]^{\star *}$} & 0.000 & {$[3.16]^{* *}$} & 0.000 & {$[2.29]^{*}$} \\
\hline Inaccess & -0.392 & {$[2.50]^{*}$} & -0.444 & {$[2.96]^{\star *}$} & -0.259 & {$[2.51]^{*}$} \\
\hline PubSpend & -0.402 & [1.52] & 0.458 & [1.90] & -0.156 & [0.93] \\
\hline Hospital & -0.028 & {$[0.18]$} & -0.142 & [1.00] & -0.163 & [1.69] \\
\hline Urban & 0.421 & [1.19] & 0.592 & {$[2.94]^{\star *}$} & 0.435 & {$[2.79]^{\star *}$} \\
\hline Income & 0.028 & {$[0.27]$} & 0.127 & {$[1.34]$} & -0.034 & {$[0.54]$} \\
\hline Prof_in_HH & 0.478 & {$[2.99]^{\star *}$} & 0.289 & [1.87] & 0.155 & [1.63] \\
\hline HH_size & -0.006 & {$[0.19]$} & -0.009 & {$[0.31]$} & -0.058 & {$[2.70]^{\star *}$} \\
\hline Age & 0.068 & [1.52] & 0.042 & [0.92] & -0.006 & {$[0.33]$} \\
\hline Age_sq & -0.001 & [1.58] & -0.001 & [1.15] & 0.000 & [0.29] \\
\hline Daughter & 0.450 & {$[2.28]^{*}$} & 0.277 & [1.72] & & \\
\hline Married & 0.490 & {$[2.24]^{*}$} & -0.016 & {$[0.08]$} & -0.009 & {$[0.11]$} \\
\hline Wom_works & 0.091 & {$[0.75]$} & 0.109 & [0.98] & 0.042 & {$[0.55]$} \\
\hline Wom_prof & 1.197 & {$[2.56]^{*}$} & 0.608 & [1.87] & -0.098 & {$[0.46]$} \\
\hline Child_of_head & & & & & 0.280 & {$[3.03]^{* *}$} \\
\hline First_child & & & & & 0.142 & {$[1.70]$} \\
\hline WomEdu & 0.196 & {$[4.14]^{* *}$} & 0.168 & {$[3.00]^{\star *}$} & 0.116 & {$[3.99]^{\star *}$} \\
\hline Spouse & -0.438 & {$[2.07]^{*}$} & 0.212 & {$[0.95]$} & -0.172 & [1.64] \\
\hline SpouseEdu & 0.077 & [1.80] & 0.029 & {$[0.49]$} & 0.082 & {$[2.84]^{* *}$} \\
\hline Oth1 & 0.093 & {$[0.56]$} & -0.030 & {$[0.20]$} & 0.121 & {$[0.99]$} \\
\hline Oth1Edu & 0.154 & {$[2.14]^{*}$} & 0.226 & {$[3.31]^{\star *}$} & 0.076 & {$[1.85]$} \\
\hline Oth1Edu x Female & 0.000 & {$[0.00]$} & 0.080 & {$[1.44]$} & 0.041 & {$[1.06]$} \\
\hline Oth2 & -0.232 & [1.23] & -0.185 & {$[0.89]$} & -0.163 & [1.18] \\
\hline Oth2Edu & 0.057 & {$[0.45]$} & -0.017 & {$[0.14]$} & 0.023 & {$[0.37]$} \\
\hline Oth2Edu x Female & -0.043 & {$[0.42]$} & 0.015 & {$[0.20]$} & 0.060 & [1.10] \\
\hline Oth3 & -0.608 & {$[2.53]^{*}$} & -0.019 & {$[0.10]$} & 0.153 & [1.28] \\
\hline Oth3Edu & 0.054 & {$[0.25]$} & -0.183 & [1.63] & 0.052 & {$[0.66]$} \\
\hline Oth3Edu x Female & -0.128 & {$[0.72]$} & 0.128 & {$[1.30]$} & -0.022 & {$[0.29]$} \\
\hline Provin=Cabo Delgado & -0.139 & {$[0.47]$} & -0.469 & [1.84] & -0.174 & [0.89] \\
\hline Provin=Nampula & -0.370 & {$[1.50]$} & -0.245 & {$[1.05]$} & -0.330 & [1.83] \\
\hline Provin=Zambezia & 0.128 & [0.53] & 0.329 & [1.43] & -0.432 & {$[2.12]^{*}$} \\
\hline Provin=Tete & 0.508 & {$[2.15]^{\star}$} & 0.460 & {$[2.00]^{\star}$} & 0.970 & {$[4.88]^{\star *}$} \\
\hline Provin=Manica & 0.252 & [0.92] & 0.245 & [0.93] & 0.064 & {$[0.31]$} \\
\hline Provin=Sofala & 0.470 & [1.78] & 0.340 & [1.41] & 0.302 & {$[1.54]$} \\
\hline Provin=Inhambane & -0.084 & [0.33] & 0.578 & {$[2.36]^{*}$} & 0.876 & {$[4.25]^{\star *}$} \\
\hline Provin=Gaza & 0.642 & {$[1.41]$} & 0.456 & {$[1.36]$} & 0.887 & {$[4.50]^{\star *}$} \\
\hline Provin=Maputo & 1.482 & {$[3.85]^{* *}$} & 0.865 & {$[3.11]^{\star *}$} & 1.207 & {$[3.65]^{\star *}$} \\
\hline Provin=Maputo Cidade & & & 0.490 & {$[1.53]$} & 1.007 & {$[2.89]^{\star *}$} \\
\hline Constant & -1.209 & [0.99] & -2.368 & {$[2.15]^{*}$} & 0.000 & {$[0.00]$} \\
\hline Observations & 1412 & & 1584 & & 3645 & \\
\hline $\ln L$ & -730.92 & & -781.82 & & -1886.91 & \\
\hline InL_O & -938.02 & & 1067.51 & & -2511.10 & \\
\hline
\end{tabular}

Note: Dummy variable for Niassa province excluded throughout. Observations from Maputo City excluded in case of pregnancy control because of perfect prediction. All estimates take into account sample weights and within-cluster correlation. Robust $z$ statistics in brackets ( ${ }^{*}$ significant at $5 \%$; ${ }^{* *}$ significant at $1 \%$ ). 
Table A5. Probit Results (education as deviation from woman's grade)

\begin{tabular}{|c|c|c|c|c|c|c|}
\hline & \multicolumn{2}{|c|}{ Pregnancy control } & \multicolumn{2}{|c|}{ Institutional delivery } & \multicolumn{2}{|c|}{ Complete immunizations } \\
\hline & coeff. & z-values & coeff. & z-values & coeff. & z-values \\
\hline Time & -0.002 & {$[4.19]^{\star *}$} & -0.002 & {$[3.63]^{\star *}$} & -0.001 & {$[3.35]^{\star *}$} \\
\hline Time_sq & 0.000 & {$[3.09]^{\star *}$} & 0.000 & {$[3.14]^{\star *}$} & 0.000 & {$[2.20]^{*}$} \\
\hline Inaccess & -0.392 & {$[2.51]^{\star}$} & -0.420 & {$[2.84]^{\star *}$} & -0.255 & {$[2.46]^{*}$} \\
\hline PubSpend & -0.419 & {$[1.56]$} & 0.442 & [1.85] & -0.159 & [0.95] \\
\hline Hospital & -0.029 & [0.18] & -0.133 & [0.94] & -0.168 & {$[1.74]$} \\
\hline Urban & 0.447 & {$[1.28]$} & 0.591 & {$[3.03]^{\star *}$} & 0.456 & {$[2.91]^{\star *}$} \\
\hline Income & 0.038 & {$[0.36]$} & 0.147 & [1.52] & -0.029 & {$[0.45]$} \\
\hline Prof_in_HH & 0.483 & {$[3.07]^{\star *}$} & 0.270 & {$[1.84]$} & 0.164 & {$[1.77]$} \\
\hline HH_size & -0.001 & [0.03] & -0.013 & {$[0.46]$} & -0.044 & {$[2.28]^{*}$} \\
\hline Age & 0.071 & {$[1.61]$} & 0.048 & [1.03] & -0.006 & {$[0.30]$} \\
\hline Age_sq & -0.001 & [1.66] & -0.001 & {$[1.24]$} & 0.000 & {$[0.33]$} \\
\hline Daughter & 0.465 & {$[2.42]^{*}$} & 0.249 & {$[1.57]$} & & \\
\hline Married & 0.500 & {$[2.28]^{*}$} & -0.006 & [0.03] & -0.024 & {$[0.31]$} \\
\hline Wom_works & 0.097 & {$[0.80]$} & 0.104 & [0.95] & 0.037 & [0.49] \\
\hline Wom_prof & 1.234 & {$[2.63]^{\star *}$} & 0.595 & [1.92] & -0.075 & {$[0.36]$} \\
\hline Child_of_head & & & & & 0.271 & {$[2.95]^{\star *}$} \\
\hline First_child & & & & & 0.153 & [1.89] \\
\hline WomEdu & 0.293 & {$[5.76]^{\star *}$} & 0.276 & {$[5.50]^{\star *}$} & 0.218 & {$[6.34]^{\star *}$} \\
\hline Spouse & -0.429 & {$[2.06]^{*}$} & 0.180 & {$[0.94]$} & -0.160 & {$[1.77]$} \\
\hline SpouseEdu' & 0.100 & {$[2.19]^{*}$} & 0.056 & [0.92] & 0.105 & {$[3.60]^{\star *}$} \\
\hline Oth1 & 0.148 & {$[0.90]$} & 0.102 & [0.69] & 0.135 & [1.22] \\
\hline Oth1Edu' & 0.144 & [1.78] & 0.227 & {$[2.56]^{*}$} & 0.083 & [1.94] \\
\hline Oth1Edu x Female' & -0.027 & {$[0.31]$} & 0.063 & {$[0.66]$} & 0.069 & [1.39] \\
\hline Oth2 & -0.239 & [1.29] & -0.139 & {$[0.77]$} & -0.154 & {$[1.21]$} \\
\hline Oth2Edu' & 0.167 & {$[1.05]$} & 0.022 & {$[0.16]$} & -0.012 & {$[0.17]$} \\
\hline Oth2Edu x Female' & -0.057 & {$[0.42]$} & 0.011 & {$[0.10]$} & 0.109 & [1.38] \\
\hline Oth3 & -0.558 & {$[2.35]^{*}$} & -0.096 & {$[0.49]$} & 0.193 & [1.68] \\
\hline Oth3Edu' & -0.223 & {$[0.93]$} & -0.139 & [0.99] & 0.032 & {$[0.29]$} \\
\hline Oth3Edu x Female' & 0.063 & {$[0.31]$} & 0.254 & [1.58] & -0.142 & [1.13] \\
\hline Provin=Cabo Delgado & -0.154 & {$[0.52]$} & -0.469 & [1.83] & -0.196 & {$[1.01]$} \\
\hline Provin=Nampula & -0.377 & [1.53] & -0.246 & {$[1.05]$} & -0.335 & {$[1.84]$} \\
\hline Provin=Zambezia & 0.128 & {$[0.53]$} & 0.336 & {$[1.45]$} & -0.430 & {$[2.13]^{\star}$} \\
\hline Provin=Tete & 0.523 & {$[2.20]^{*}$} & 0.463 & {$[1.98]^{*}$} & 0.970 & {$[4.86]^{\star *}$} \\
\hline Provin=Manica & 0.279 & [0.98] & 0.226 & {$[0.86]$} & 0.037 & {$[0.18]$} \\
\hline Provin=Sofala & 0.470 & {$[1.77]$} & 0.328 & [1.35] & 0.293 & [1.51] \\
\hline Provin=Inhambane & -0.054 & {$[0.21]$} & 0.602 & {$[2.44]^{*}$} & 0.885 & {$[4.35]^{\star *}$} \\
\hline Provin=Gaza & 0.668 & [1.49] & 0.472 & [1.38] & 0.874 & {$[4.41]^{\star *}$} \\
\hline Provin=Maputo & 1.465 & {$[3.85]^{* *}$} & 0.857 & {$[3.11]^{\star *}$} & 1.179 & {$[3.60]^{* *}$} \\
\hline Provin=Maputo Cidade & & & 0.479 & {$[1.46]$} & 1.087 & {$[3.37]^{\star *}$} \\
\hline Constant & -1.454 & {$[1.21]$} & -2.720 & {$[2.40]^{*}$} & -0.199 & {$[0.31]$} \\
\hline Observations & 1412 & & 1584 & & 3645 & \\
\hline $\ln L$ & -730.04 & & -780.16 & & -1884.26 & \\
\hline InL_O & -938.02 & & -1067.51 & & -2511.10 & \\
\hline
\end{tabular}

Note: Dummy variable for Niassa province excluded throughout. Observations from Maputo City excluded in case of pregnancy control because of perfect prediction. All estimates take into account sample weights and within-cluster correlation. Robust $z$ statistics in brackets (* significant at $5 \%$; ${ }^{* *}$ significant at $1 \%)$. 
Table A6. Test statistics for Estimated Coefficients (education as deviation)

\begin{tabular}{|c|c|c|c|}
\hline \multirow[t]{2}{*}{$H_{0}$} & \multicolumn{3}{|c|}{ Prob. $\mathrm{H}_{0}$ is true (Chi2) } \\
\hline & Preg. cont. & Inst. dlvry. & Immun. \\
\hline $\begin{array}{l}\text { Oth2Edu' }= \\
\text { Oth2Edu' + }(\text { Oth2Edu' } \times \text { Female })= \\
\text { Oth3Edu' }= \\
\text { Oth3Edu' }+(\text { Oth3Edu' } \times \text { Female })=0\end{array}$ & 0.814 & 0.628 & 0.448 \\
\hline $\begin{array}{l}\text { Oth1Edu' } \times \text { Female }= \\
\text { Oth2Edu' } \times \text { Female }= \\
\text { Oth3Edu' } \times \text { Female }=0\end{array}$ & 0.943 & 0.331 & 0.065 \\
\hline $\begin{array}{l}\text { Oth2Edu' } \times \text { Female }= \\
\text { Oth3Edu' } \times \text { Female }=0\end{array}$ & 0.847 & 0.282 & 0.163 \\
\hline
\end{tabular}

Table A7. Test of Coefficient Equality across Subsamples

\begin{tabular}{|c|c|c|c|}
\hline \multirow{2}{*}{$\begin{array}{l}H_{0}: \text { coefficients estimated over sub-sample of } \\
\text { women with no education are equal to } \\
\text { those estimated over sub-sample of } \\
\text { women with some education }\end{array}$} & \multicolumn{3}{|c|}{ Prob. $\mathrm{H}_{0}$ is true (Chi2) } \\
\hline & Preg. cont. & Inst. dlvry. & Immun. \\
\hline Spouse_edu & 0.977 & 0.221 & 0.023 \\
\hline Oth1_edu & 0.437 & 0.174 & 0.224 \\
\hline $\begin{array}{l}\text { Oth1_edu } \\
\text { Oth1_edu + (Oth1Edu x Female) }\end{array}$ & 0.549 & 0.373 & 0.353 \\
\hline
\end{tabular}

Table A8. Test of Alternative Non-nested Specification

\begin{tabular}{lc}
\hline $\begin{array}{l}\text { HO: the alternative set of conditioning variables (education measured as } \\
\text { deviation from woman's education, with lower bound of zero) is more } \\
\quad \text { appropriate }\end{array}$ & $t$-value \\
\hline Pregnancy control & 0.518 \\
Institutional delivery & 0.019 \\
Child immunizations & 0.015 \\
\hline
\end{tabular}

${ }^{*}$ A large $t$-value is evidence in favor of the alternative specification. 
Figure 1. Female Education and Health Service Outcomes

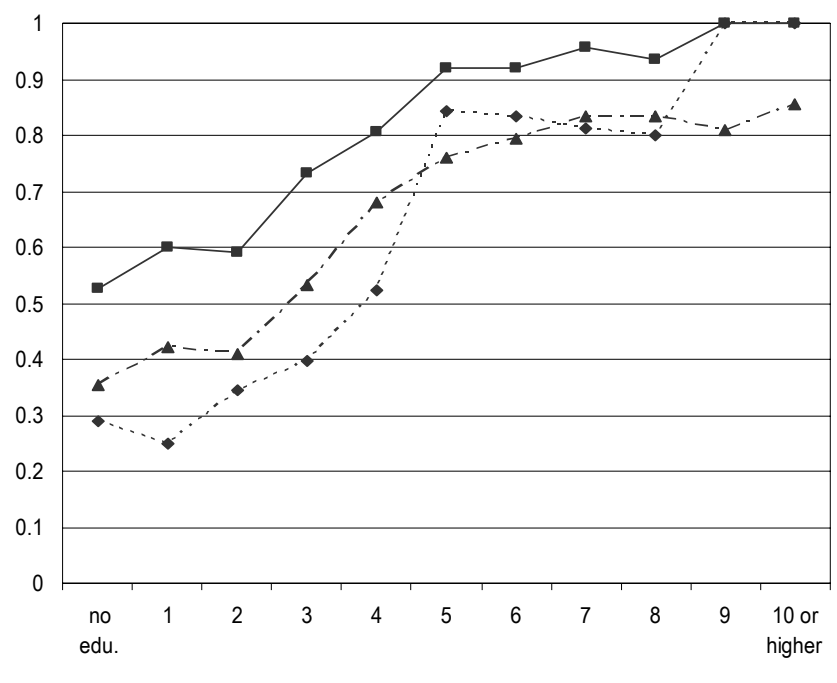

Highest grade attained

$\longrightarrow$ Preg. control -..- - Inst delivery - - - - Comp. immun.

Figure 2. Impact of Women's Own Education on Predicted Probs.

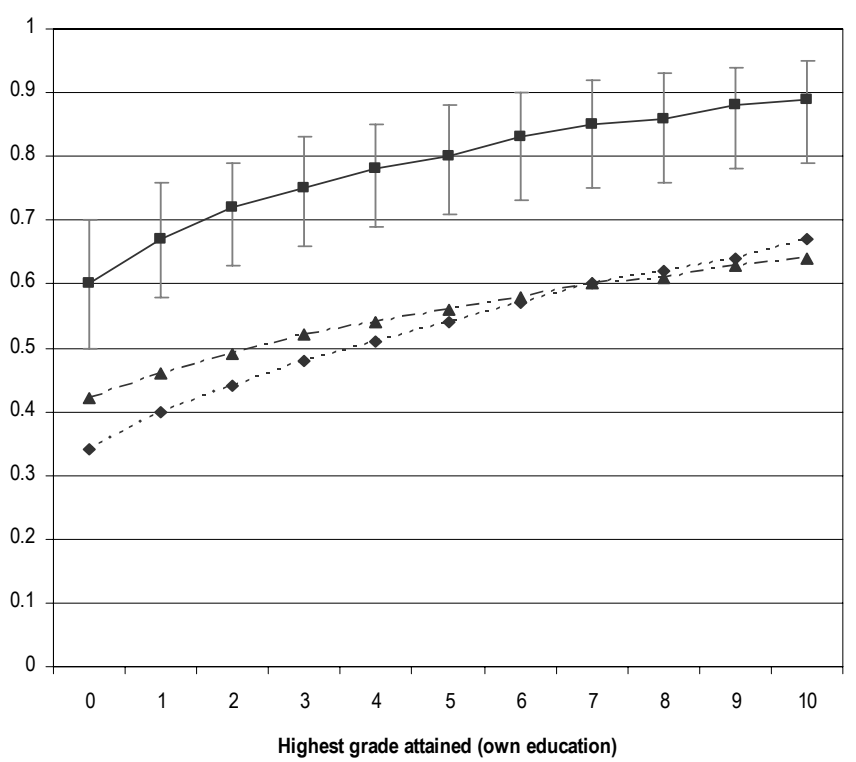

$\longrightarrow$ Preg. control -..- Inst delivery - - - - Comp. immun.

Note: All predicted probabilities are calculated at the sample means of the independent variables, and for the full range of the respective education variable. Where relevant, dummy variables are also varied to reflect the presence of the spouse or "other" person in the household. The 95 percent confidence interval is shown for one of the health care choices. 
Figure 3. Impact of Spousal Education on Predicted Probs.

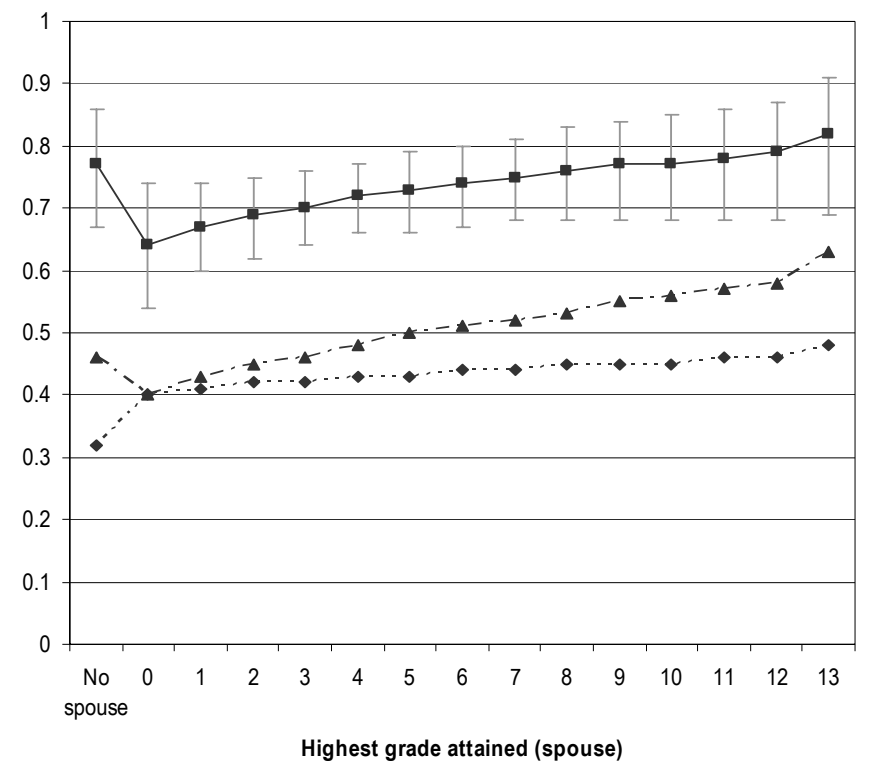

$\longrightarrow$ Preg. control ...-.. Inst delivery - - - - Comp. immun.

Figure 4. Impact of the Education of Other HH Member on Predicted Probs.

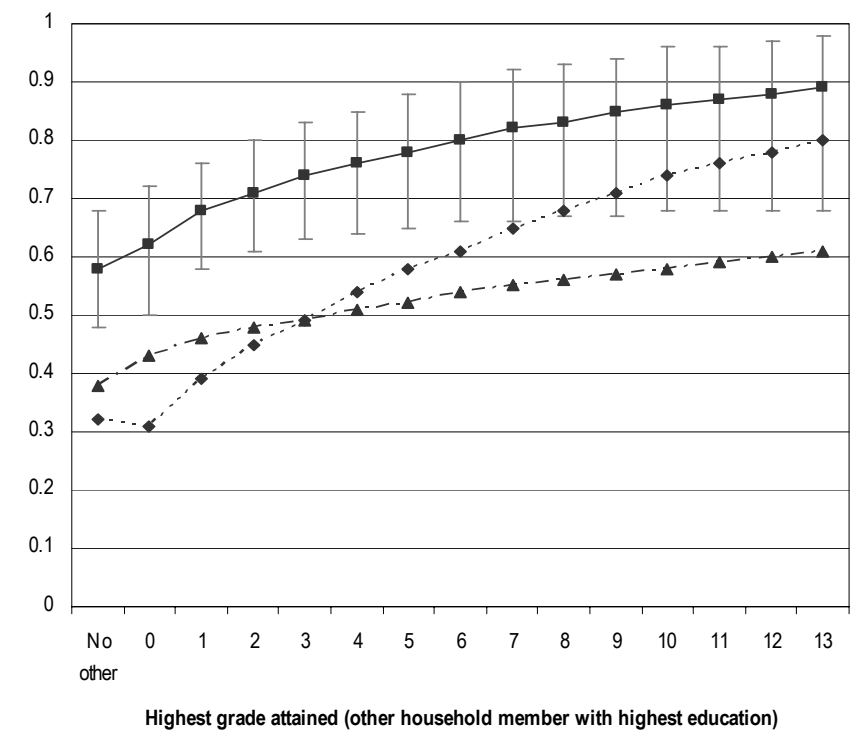

$\longrightarrow$ Preg. control - . - - Inst. delivery - - - - Comp. immun. 


\section{References}

The word "processed" describes informally reproduced works that may not be commonly available through library systems.

Akin, J., C. Griffin, D. K. Guilkey, and B. M. Popkin. 1986. "The Demand for Primary Health Care Services in the Bicol Region of the Philippines." Economic Development and Cultural Change 34(4): 755-82.

Akin, J., S. C. Griffin, D. K. Guilkey, and B. M. Popkin. 1984. The Demand for Primary Health Care in Developing Countries. Totowa, N.J.: Littlefield, Adams.

Barrera, A. 1990. "The role of maternal schooling and its interaction with public health programs in child health production." Journal of Development Economics 32: 69-91.

Basu, K., and J. E. Foster. 1998. “On Measuring Literacy.” Economic Journal 108: 1733-49.

Basu, K., J. E. Foster, and S. Subramanian. 2001. "Isolated and proximate illiteracy and why these concepts matter in measuring literacy and designing education programmes." Working Paper 00-W02. Vanderbilt University Economics Department. Processed.

Basu, K., A. Narayan, and M. Ravallion. 2002. "Is literacy shared within households? Theory and evidence for Bangladesh." Labour Economics 8: 649-65.

Becker, G. 1965. "A theory of the allocation of time." Economic Journal 75: 493-517.

Behrman, J., and B. Wolfe. 1987. "How does mother's schooling affect family health, nutrition, medical care usage and household sanitation?" Journal of Econometrics 36: 185-204.

Behrman, J. R., and A. B. Deolalikar. 1988. "Health and Nutrition." In Chenery and Srinivasan, eds., Handbook of Development Economics. Volume 1. Handbooks in Economics, vol. 9. Amsterdam; New York and Oxford: Elsevier Science, pp. 631-711.

Benefo, K., and P. T. Schulz. 1996. "Fertility and child mortality in Cote d'Ivoire and Ghana." World Bank Economic Review 10(1): 123-58.

Bicego, G. T., and J. T. Boerma. 1993. "Maternal education and child survival. A comparative study of survey data from 17 countries." Social Science \& Medicine 36: 1207-27.

Caldwell, J. 1979. "Education as a factor in mortality decline: an examination of Nigerian data." Population Studies 33(3): 395-413.

Cebu Study Team. 1991. "Underlying and proximate determinants of child health: The Cebu longitudinal health and nutrition study." American Journal of Epidemiology 133(2): 185-201.

Datt, G., K. Simler, S. Mukherjee, and G. Dava. 2000. "Determinants of poverty in Mozambique: 1996-97." FCND discussion paper 78. IFPRI.

Davidson, R., and J. MacKinnon. 1993. Estimation and Inference in Econometrics. Oxford: Oxford University Press.

Desai, S., and S. Alva. 1998. "Maternal education and child health: Is there a strong causal relationship." Demography 35(1): 71-81.

Dow, W. H. 1996. "Discrete Choice Estimation of Price-Elasticities: The Benefits of a Flexible Behavioural Model of Health Care Demand.” Processed. 
Foster, A. D., and M. R. Rosenzweig. 1996. "Technical change and human capital returns and investments: Evidence from the Green Revolution." American Economic Review 86: 931-53.

Gage, A., A. E. Sommerfelt, and A. L. Piani. 1997. "Household structure and childhood immunization in Niger and Nigeria." Demography 34(2): 295-309.

Gertler, P., L. Locay, and W. Sanderson. 1987. "Are user fees regressive? The welfare implications of health care financing proposals in Peru." Journal of Econometrics 36:suppl.: 67-88.

Gertler, P., O. Rahman, and C. Feifer. 1993. "Determinants of pregnancy outcomes and targeting of maternal health services in Jamaica." Social Science and Medicine 37(2): 199-211.

Gertler, P., and J. van der Gaag. 1990. The willingness to pay for medical care: Evidence from two developing countries. Baltimore and London: Johns Hopkins University Press for the World Bank.

Gibson, J. 1999. “Literacy and Intrahousehold Externalities.” University of Waikato, New Zealand. Processed.

Glewwe, P. 1999. "Why Does Mother's Schooling Raise Child Health in Developing Countries? Evidence from Morocco." Journal of Human Resources XXXIV(1): 124-59.

Glewwe, P. 2000. "Education." In Grosh and Glewwe, eds., Designing Household Survey Questionnaires for Developing Countries: Lessons from 15 Years of the Living Standards Measurement Study. Washington, D.C.: The World Bank.

Green, S., T. Rich, and E. Nesman. 1985. "Beyond individual literacy: the role of shared literacy for innovation in Guatemala." Human Organization 44(4): 31321.

Grossman, M. 1972a. The Demand for Health: A Theoretical and Empirical Investigation. New York: National Bureau of Economic Research.

Grossman, M. 1972b. "On the Concept of Health Capital and the Demand for Health." Journal of Political Economy 80(2): 223-55.

Guilkey, D., and R. Riphahn. 1998. "The determinants of child mortality in the Philippines: Estimation of a structural model." Journal of Development Economics 56: 281-305.

Hobcraft, J. 1993. "Women's education, child welfare and child survival: a review of the evidence." Health Transition Review 3(2): 159-75.

Hossain, S. 1989. "Effects of public programs on family size, child education and health." Journal of Development Economics 30(1): 145-58.

Lavy, V., J. Strauss, D. Thomas, and P. D. Vreyer. 1996. "Quality of Health Care, Survival and Health Outcomes in Ghana.” Journal of Health Economics 15(3): 333-57.

Ministry of Planning and Finance. 1998. "Understanding Poverty and Well-Being in Mozambique: The First National Assessment (1996-97).” Ministry of Planning and Finance (Mozambique), Universidade Eduardo Mondlane, International Food Policy Research Institute.

Mwabu, G. 1986. "Health Care Decisions at Household Level: Results of Health Survey in Kenya." Social Science and Medicine 22(3): 313-19.

Panis, C., and L. Lillard. 1994. "Health inputs and child mortality." Journal of Health Economics 13: 455-89. 
Pebley, A. R., N. Goldman, and G. Rodriguez. 1996. "Prenatal and Delivery Care and Childhood Immunization in Guatemala: Do Family and Community Matter?" Demography 33(2): 231-47.

Ryan, G. W. 1981. "Non-use of physicians: Methodological approaches, policy implications, and the utility of decision models." Social Science and Medicine 15B: 499-507.

Ryan, G. W. 1998. "What do sequential behavioral patterns suggest about the medical decision-making process? modeling home case management of acute illnesses in a rural Cameroonian village." Social Science and Medicine 46(2): 209-25.

Ryan, G. W. and H. Martinez. 1996. "Can we predict what mothers do? Modeling Childhood Diarrhea in Rural Mexico." Human Organization 55(1): 47-56.

Sandiford, P., J. Cassel, M. Montenegro, and G. Sanchez. 1995. "The Impact of Women's Literacy on Child Health and its Interaction with Access to Health Services." Population Studies 49(1): 5-17.

Schultz, T. P. 1984. "Studying the impact of household economic and community variables on child mortality." Population and Development Review 10: 215-35.

Schultz, T. P. 1999. "Health and Schooling Investments in Africa." Journal of Economic Perspectives 13(3).

Schwartz, J. B., J. S. Akin, and B. M. Popkin. 1988. "Price and Income Elasticities of Demand for Health Care: The Case of the Infant Delivery in the Philippines." The World Bank Economic Review 2(1): 49-76.

Steele, F., I. Diamond, and S. Amin. 1996. "Immunization Uptake in Rural Bangladesh: A Multilevel Analysis." Journal of the Royal Statistical Society 159(2): 289-99.

Strauss, J., and D. Thomas. 1995. "Human Resources: Empirical Modeling of Household and Family Decisions." In Behrman and Srinivasan, eds., Handbook of development economics. Volume 3A. Handbooks in Economics, vol. 9. Amsterdam; New York and Oxford: Elsevier Science, pp. 1883-2023.

Strauss, J., and D. Thomas. 1998. "Health, Nutrition, and Economic Development." Journal of Economic Literature 36(2): 766-817.

Streatfield, K., M. Singarimbun, and I. Diamond. 1990. "Maternal education and child immunization.” Demography 27(3): 447-55.

Subramanian, S. 2001. "Equity, Efficiency, and the Measurement of Literacy: Some Extensions of the Basu-Foster Framework." Madras Institute of Development Studies. Processed.

Thomas, D., J. Strauss, and M. Henriques. 1990. "Child survival, height for age, and household characteristics in Brazil." Journal of Development Economics 33: 197-234.

Wolfe, B. L., and J. R. Behrman. 1982. "Determinants of child mortality, health and nutrition in a developing country." Journal of Development Economics 11: 16393.

Wolfe, B. L., and J. R. Behrman. 1984. "Determinants of women's health status and health-care utilization in a developing country." Review of Economics and Statistics 56: 696-703.

Wong, E., B. Popkin, D. Guilkey, and J. Akin. 1987. "Accessibility, quality of care and prenatal care use in the Philippines." Social Science and Medicine 24(11): 927-44. 